\title{
ARTICLE OPEN Metabolic programming determines the lineage-differentiation fate of murine bone marrow stromal progenitor cells
}

\author{
Michaela Tencerova (iD) ${ }^{1}$, Elizabeth Rendina-Ruedy ${ }^{2}$, Ditte Neess ${ }^{3}$, Nils Færgeman ${ }^{3}$, Florence Figeac ${ }^{1}$, Dalia Ali $^{1}$, Morten Danielsen $^{4}$, \\ Anders Haakonsson ${ }^{1}$, Clifford J. Rosen ${ }^{2}$ and Moustapha Kassem ${ }^{1,5}$
}

Enhanced bone marrow adipogenesis and impaired osteoblastogenesis have been observed in obesity, suggesting that the metabolic microenvironment regulates bone marrow adipocyte and osteoblast progenitor differentiation fate. To determine the molecular mechanisms, we studied two immortalized murine cell lines of adipocyte or osteoblast progenitors (BMSCs ${ }^{\text {adipo }}$ and $\mathrm{BMSCs}^{\text {osteo }}$, respectively) under basal and adipogenic culture conditions. At baseline, $\mathrm{BMSCs}{ }^{\text {adipo }}$, and $\mathrm{BMSCs}^{\text {osteo }}$ exhibit a distinct $^{\text {a }}$ metabolic program evidenced by the presence of specific global gene expression, cellular bioenergetics, and metabolomic signatures that are dependent on insulin signaling and glycolysis in BMSCs ${ }^{\text {osteo }}$ versus oxidative phosphorylation in BMSCs ${ }^{\text {adipo }}$. To test the flexibility of the metabolic program, we treated BMSCs ${ }^{\text {adipo }}$ with parathyroid hormone, S961 (an inhibitor of insulin signaling) and oligomycin (an inhibitor of oxidative phosphorylation). The treatment induced significant changes in cellular bioenergetics that were associated with decreased adipocytic differentiation. Similarly, 12 weeks of a high-fat diet in mice led to the expansion of adipocyte progenitors, enhanced adipocyte differentiation and insulin signaling in cultured BMSCs. Our data demonstrate that BMSC progenitors possess a distinct metabolic program and are poised to respond to exogenous metabolic cues that regulate their differentiation fate.

Bone Research (2019)7:35 ～； https://doi.org/10.1038/s41413-019-0076-5

\section{INTRODUCTION}

Bone marrow (BM) is a heterogeneous organ that contains, in addition to hematopoietic stem cells, BM stromal (also known as skeletal or mesenchymal) stem cells (BMSCs) and their descendent progenitors of adipocyte (AD) and osteoblast (OB) lineages that give rise to BM adipose tissue (BMAT) and bone, respectively. ${ }^{1-5}$

The differentiation of BMSCs is regulated by a variety of extracellular factors present in the BM microenvironment. ${ }^{3,6}$ Metabolic changes in obesity, type 2 diabetes, and anorexia nervosa lead to differential effects on BMSC differentiation capacity and are associated with increased BMAT formation, ${ }^{7}$ suggesting that the metabolic state of the organism regulates BMSC differentiation fate.

In a number of stem cell models, such as pluripotent embryonic stem cells, hematopoietic, muscle stem cells $s^{8-10}$ and immune cells, ${ }^{11}$ cellular differentiation and functions are determined by the cellular metabolic and bioenergetic state. ${ }^{12}$ Pluripotent embryonic stem cells prefer anabolic glycolysis, which is also the preferred metabolic process of rapidly proliferating cells., ${ }^{8,13}$ In addition, hematopoietic progenitor cells exhibit differentiation-dependent use of glycolysis or oxidative phosphorylation (OxPhos). ${ }^{14,15}$ Similarly, during extramedullary AD differentiation, a switch in the bioenergetic program from glycolysis to OxPhos has been observed and provides AD progenitors with sufficient energy for histone acetylation and activation of the lipogenic and adipogenic program. ${ }^{16}$ On the other hand, during mid to late $\mathrm{OB}$ differentiation, glycolysis is the preferred bioenergetic mechanism. ${ }^{17}$ These data suggest that the differentiation responses of progenitor cells to metabolic changes in their microenvironment are dependent on their bioenergetic state and substrate choice. ${ }^{18}$ However, it is not known whether a specific metabolic program of BMSC progenitors exists and whether it determines their differentiation responses.

To address this question, we employed two immortalized murine cell lines of progenitor cells that are committed towards either $\mathrm{AD}$ or $\mathrm{OB}$ (BMSCs ${ }^{\text {adipo }}$ and $\mathrm{BMSCs}^{\text {osteo }}$, respectively) as they represent two alternative differentiation choices of BMSCs in vivo. These cell lines have previously been established and characterized in our laboratory. ${ }^{19-21}$ We tested the hypothesis that there exists a distinct metabolic program in BMSC progenitors that determines their differentiation responses to exogenous metabolic cues. Applying the global approaches of transcriptional and metabolomics analyses, we demonstrate that $A D$ versus $O B$ progenitors exhibit a unique bioenergetic profile and intrinsic metabolic program that is responsive to the exogenous cue of insulin and regulates their differentiation outcome. We corroborated these findings by reporting similar changes in BMSC differentiation capacity in vivo under conditions of metabolic changes related to high-fat diet (HFD)-induced obesity in mice.

\footnotetext{
${ }^{1}$ Department of Molecular Endocrinology, University of Southern Denmark and Odense University Hospital, 5000 Odense, Denmark; ${ }^{2}$ Center for Molecular Medicine, Maine Medical Center Research Institute, Scarborough, ME 04074, USA; ${ }^{3}$ Villum Center for Analytical Biosciences, Department of Biochemistry and Molecular Biology, University of

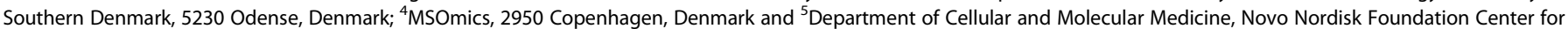
Stem Cell Biology (DanStem), University of Copenhagen, 2200 Copenhagen, Denmark

Correspondence: Michaela Tencerova (mtencerova@health.sdu.dk)
}

Received: 17 March 2019 Revised: 22 July 2019 Accepted: 18 August 2019

Published online: 14 November 2019 


\section{RESULTS}

$\mathrm{BMSCs}^{\text {adipo }}$ and $\mathrm{BMSCs}^{\text {osteo }}$ progenitors exhibit a unique gene expression profile

BMSC cultures represent a heterogeneous population of cells that include stem cells and their descendent progenitors at different stages of differentiation. ${ }^{4,22}$ To avoid confounding variables mediated by different cell populations present within primary cultures, we employed two immortalized murine lines that were functionally defined by their ability to differentiate into either $A D$ $\left(\mathrm{BMSCs}^{\text {adipo }}\right)$ or OB (BMSCs $\left.{ }^{\text {osteo }}\right)^{19}$ (Fig. 1a). To identify the presence of a molecular signature of bioenergetic and metabolic programs, we performed global gene expression profiling under basal conditions ${ }^{20,21}$ that revealed differential enrichment of genes associated with the following metabolic pathways: insulin signaling, PPAR signaling, fatty acid oxidation, glycolysis and cell adhesion, cell cycle, immune system, and purine metabolism in $\mathrm{BMSCs}^{\text {adipo }}$ versus BMSCs ${ }^{\text {osteo }}$ (Fig. $1 \mathrm{~b}$ and Fig. S1). Concordant changes in the expression of a representative group of genes were confirmed by qRT-PCR (Fig. 1c-k). Compared with BMSCs ${ }^{\text {osteo, }}$ gene expression profiling of $\mathrm{BMSCs}^{\text {adipo }}$ revealed increased expression of insulin-responsive genes (Irs1, Irs2, Insr, and Foxo1) (Fig. 1c), glucose transporters (Glut4) (Fig. 1d), adipocytic genes (Ppary2, Clepba, Lep, and Adipoq) (Fig. 1e), lipid metabolism genes (Fsp27, Cidea, Cd36, and Hsl) (Fig. 1f), autophagy (Atg7, Lc3b, and Beclin1) (Fig. 1g), bioenergetic genes (Ucp, Prdm16, Mttp, and Ppara) (Fig. 1h), inflammatory genes (II1 $\beta$, Tnfa, and Lcn2) (Fig. 1i), and senescence-associated markers (p21, p53, Fasl, Hmox1, and Sod2) (Fig. 1j). As expected, BMSCs adipo expressed lower levels of osteoblastic genes (Fig. 1k). We employed this molecular signature to test the flexibility of the BMSCs ${ }^{\text {adipo }}$ and $\mathrm{BMSCs}^{\text {osteo }}$ phenotypes in response to adipogenic culture conditions that promote $A D$ differentiation. As shown in Fig. S2a-e, adipogenic culture conditions promoted $\mathrm{AD}$ formation only in $\mathrm{BMSCs}^{\text {adipo }}$ but not in $\mathrm{BMSCs}^{\text {osteo }}$. In addition, the gene expression profile of adipocytic genes and genes associated with insulin signaling, glucose transporter, lipid metabolism, and autophagy were

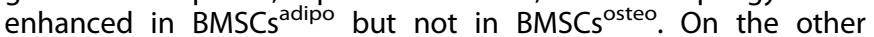
hand, BMSCs ${ }^{\text {osteo }}$ exhibited higher gene expression levels of $\mathrm{OB}$ marker genes (Oc, Alpl, Bmp2, and Pth1r), which were more robust in the presence of $O B$ differentiation induction medium, along with increased Alkaline phosphatase (ALP) activity and no effect on adipocytic marker genes in compared with those in BMSCs adipo (Fig. 1k, Fig. S2f-h). These data corroborate that BMSCs ${ }^{\text {adipo }}$ and BMSCs ${ }^{\text {osteo }}$ progenitors are committed progenitors poised to respond to metabolic and nutrient stimuli and that they exhibit significant differences in the gene expression levels of metabolic and bioenergetic genes.

$\mathrm{BMSCs}^{\text {adipo }}$ and $\mathrm{BMSCs}{ }^{\text {osteo }}$ progenitors exhibit differential responses to insulin

To investigate the responsiveness of $\mathrm{BMSCs}^{\text {adipo }}$ and $\mathrm{BMSCs}^{\text {osteo }}$ to the metabolic environment, we determined the responses to insulin as the major regulator of cellular energy metabolism. $\mathrm{BMSCs}^{\text {adipo }}$ exhibited higher levels of insulin signaling genes (Fig. 1c) and enhanced responsiveness to insulin compared with those of BMSCs ${ }^{\text {osteo }}$ as measured by pAKT(Ser-473)/total AKT (Fig. 2a, b and Fig. S3a, b, left panels), and this occurs at baseline and when cultured under adipogenic conditions. In addition, insulin receptor (INSR) protein levels were higher in BMSCs adipo compared with BMSCs $^{\text {osteo }}$ (Fig. 2a, b, Fig. S3a, b, right panels).

$\mathrm{BMSC}^{\text {adipo }}$ exhibit higher insulin-dependent glucose utilization and de novo lipogenesis compared with those of BMSCs ${ }^{\text {osteo }}$ Since BMSCs ${ }^{\text {adipo }}$ were more insulin-responsive at baseline and under adipogenic conditions, we investigated functional insulin responses in the two immortalized progenitor cell lines (Fig. 2c, d). $\mathrm{BMSCs}^{\text {adipo }}$ were more responsive to insulin stimulation, as reflected by the higher glucose uptake under baseline and adipogenic culture conditions (Fig. 2c, d). In addition at baseline, glucose uptake (Fig. 2c, d) was higher in BMSCs ${ }^{\text {osteo }}$ compared with uptake in BMSCs ${ }^{\text {adipo. }}$.

At baseline, de novo synthesized lipids determined by thin layer chromatography (TLC) analysis were undetectable (data not shown), while following treatment with adipogenic culture conditions, BMSCs ${ }^{\text {adipo }}$ exhibited higher levels of insulinmediated glucose incorporation into fatty acids (FA) and triglyceride (TG) (Fig. 2e, f), which was similar to what was observed in 3T3-L1 cells. ${ }^{23}$ BMSCs ${ }^{\text {osteo }}$ did not accumulate lipids (Fig. 2e, f). Additional studies employing radiolabeled ${ }^{14} \mathrm{C}$ glucose detected the incorporation of glucose into lipids (FA and TG), demonstrating de novo lipogenesis in BMSCs adipo and 3T3-L1 but not in BMSCs ${ }^{\text {osteo }}$ under adipogenic culture conditions (Fig. $2 \mathrm{~g}, \mathrm{~h}$ ).

$\mathrm{BMSCs}^{\text {adipo }}$ and BMSCs ${ }^{\text {osteo }}$ exhibit a distinct bioenergetic profile Since BMSCs ${ }^{\text {adipo }}$ and $\mathrm{BMSCs}^{\text {osteo }}$ exhibit well-defined differences in their metabolic molecular signature and insulin responsiveness, we investigated the functional consequences on their bioenergetic profile using a Seahorse XF24 analyzer. The cells were studied under the basal state and following incubation in adipogenic culture conditions. We obtained simultaneous measurements of mitochondrial function via the oxygen consumption rate $(\mathrm{OCR})$ and glycolysis via the extracellular acidification rate (ECAR) employing the Glyco and Mito Stress test (Fig. 3).

In the Glyco Stress test, ECAR revealed higher basal glycolytic activity and maximal glycolytic capacity in BMSCs ${ }^{\text {osteo }}$ compared with those in BMSCs ${ }^{\text {adipo }}$, and this was observed both at baseline (Fig. 3a) and following incubation under adipogenic culture conditions (Fig. 3b). On the other hand, the Mito Stress test showed similar OxPhos activity at baseline between BMSCs ssteo and $\mathrm{BMSCs}^{\text {adipo }}$ (Fig. 3c, left panel). In addition, BMSCs ${ }^{\text {osteo }}$ maintained higher glycolytic activity (Fig. 3c, right panel). Following 10 days of incubation under adipogenic culture conditions, BMSCs adipo demonstrated elevated basal OCR, and following mitochondrial uncoupling with carbonyl cyanide-4(trifluoromethoxy) phenylhydrazone (FCCP), their maximal OCR was dramatically increased (Fig. 3d, left panel). Conversely, $\mathrm{BMSCs}^{\text {osteo }}$ exhibited reduced basal and maximal OCR (mitochondrial respiration) (Fig. 3d, left panel) while maintaining higher glycolytic activities (Fig. 3d, right panel). Furthermore, when BMSCs ${ }^{\text {adipo }}$ and BMSCs ${ }^{\text {osteo }}$ were exposed to insulin $\left(100 \mu \mathrm{mol} \cdot \mathrm{L}^{-1}\right)$, they exhibited significant differences in their bioenergetic profile with enhanced OxPhos in BMSCs ${ }^{\text {adipo }}$ and not in BMSCs ${ }^{\text {osteo }}$ that maintained a glycolytic profile (Fig. $3 e, f$ ).

These data demonstrate that BMSCs ${ }^{\text {adipo }}$ exhibit a distinct bioenergetic profile associated with different strategies for glucose utilization compared with that of $\mathrm{BMSCs}^{\text {osteo }}$.

$\mathrm{BMSCs}^{\text {adipo }}$ and BMSCs ${ }^{\text {osteo }}$ exhibit significant differences in their metabolite composition

To corroborate the observed changes in the bioenergetic profile, we performed a global metabolomic comparison of BMSCs adipo and $\mathrm{BMSCs}^{\text {osteo }}$ in undifferentiated conditions using liquid chromatography-mass spectrometry (LC-MS) (Fig. 4). A heat map of intracellular metabolites revealed a unique profile with significant differences detectable at baseline (Fig. 4a). We found that adenosine-5'-monophosphate, guanosine-5'-monophosphate, uridine-5'-monophosphate, glutamine, and glucose-6phosphate were the major metabolites that distinguish

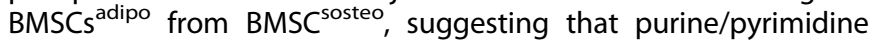
and glucose metabolism are key processes associated with $A D$ lineage commitment. On the other hand, the major metabolites in BMSCs $^{\text {osteo }}$ were proline, choline, glyceraldehyde, and serine, which may be related to the capacity for extracellular matrix production (Fig. 4b).

Additional targeted analysis of metabolites using LC-MS identified several specific compounds, such as phosphocholine, 


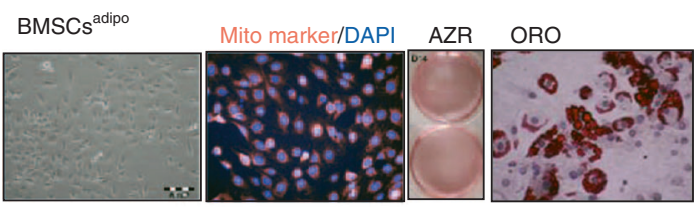

BMSCs $^{\text {osteo }}$

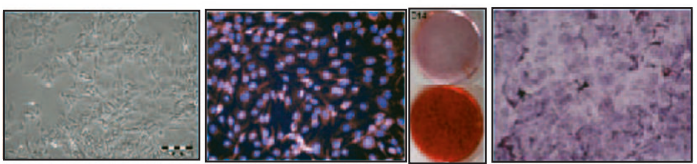

b

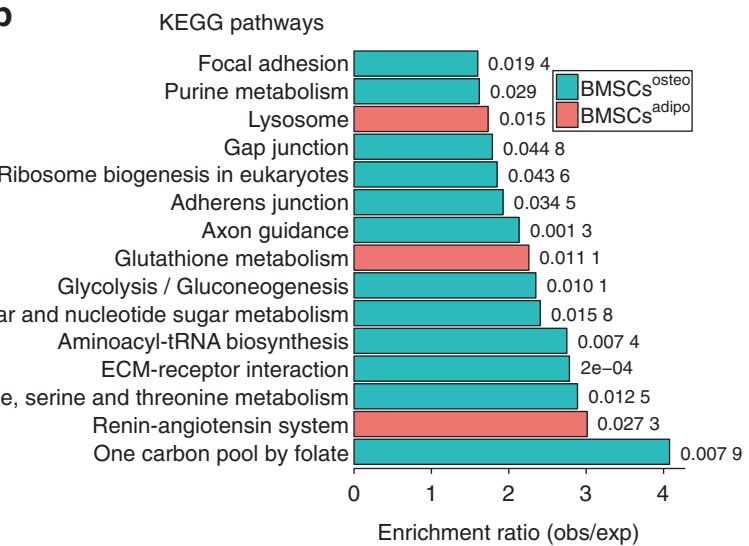

$\square$ BMSCs $^{\text {adipo }}$

BMSCs ${ }^{\text {osteo }}$
C

Insulin signaling genes (F.C.)

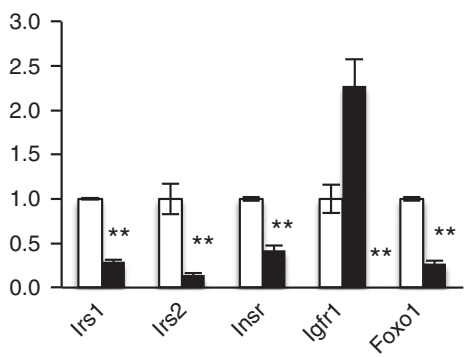

f

Lipid metabolism genes (F.C.)

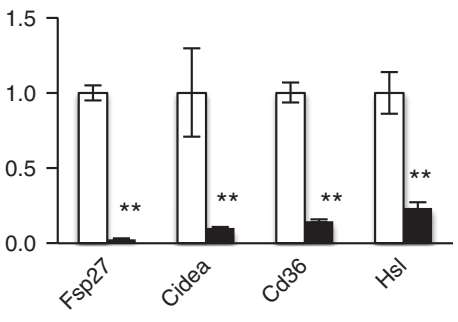

Inflammatory genes (F.C.)

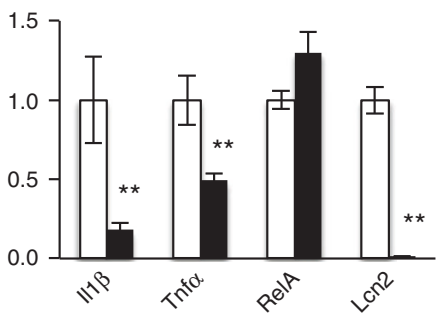

d

Glucose transporters (F.C.)

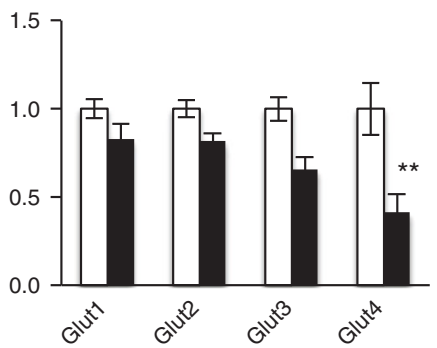

g

Autophagy genes (F.C.)

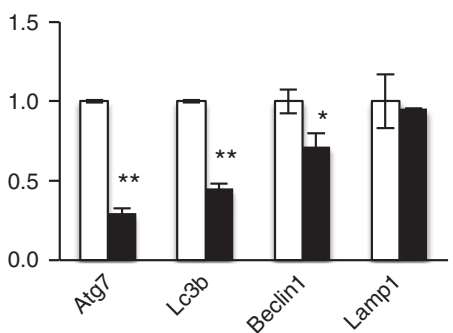

j

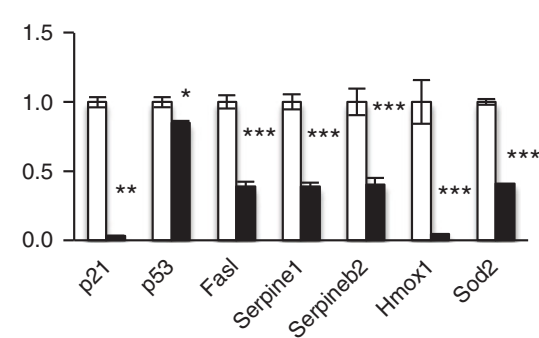

Adipocytic genes (F.C.)
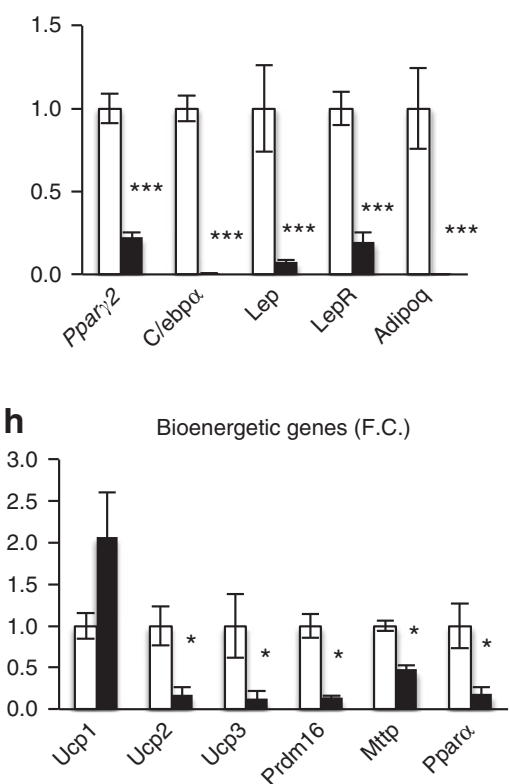

K

Osteoblast markers genes (F.C.)

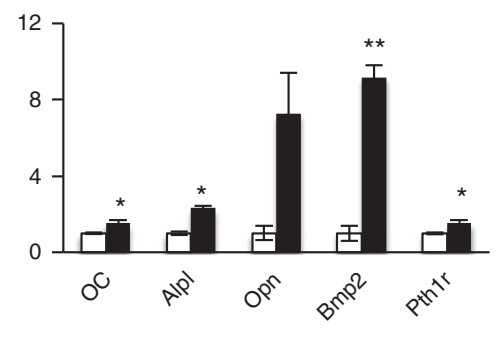

Fig. $1 \mathrm{BMSCs} \mathrm{sdipo}^{\text {and }} \mathrm{BMSCs}^{\text {osteo }}$ progenitors exhibit a unique gene expression profile. a Representative pictures of $\mathrm{BMSCs}{ }^{\text {adipo }}$ and BMSCs ${ }^{\text {osteo }}$ with mitochondrial staining using MitoTracker (red), Alizarin staining (AZR) for matrix mineralization and Oil Red O staining (ORO) showing the morphological and differentiation-induced differences between the murine cell lines. $\mathbf{b}$ Enrichment of genes of functional GO categories from microarray. Gene expression profiling in BMSCs adipo (white bars) and BMSCs ${ }^{\text {osteo }}$ cultured in basal conditions (black bars): c genes involved in insulin signaling such as Irs1, Irs2, Insr, Igfr1, and Foxo1; d glucose transporters such as Glut1, Glut2, Glut3, and Glut4; e adipocytic genes such as Ppary2, C/ebpa, Lep, LepR, and Adipoq; f genes involved in lipid metabolism such as Fsp27, Cidea, Cd36, and Hsl; g autophagy genes such as Atg7, Lc3b, Beclin1, and Lamp1; h bioenergetic genes such as Ucp1, Ucp2, Ucp3, Prdm16, Mttp, and Ppara; i inflammatory genes such as II1 $\beta$, Tnfa, Mcp1, RelA, and Lcn2; j senescence-associated markers such as p21, p53; Fasl, Serpine1, Serpineb2, Hmox1, and Sod2; $\mathbf{k}$ osteoblast marker genes such as Oc, Opn, Alpl, Bmp2, and Pthr1. Data are presented as the mean fold change (F.C.) of gene expression normalized to BMSCs ${ }^{\text {adipo }}$ expression \pm SEM, $\left(n=3\right.$ per group); $\left({ }^{*} P<0.05,{ }^{* *} P<0.01 ;{ }^{* *} P<0.001\right.$ : BMSCs ${ }^{\text {adipo }}$ vs BMSCs $^{\text {osteo }}$, twotailed unpaired Student's $t$ test) 
a

Undifferentiated cells

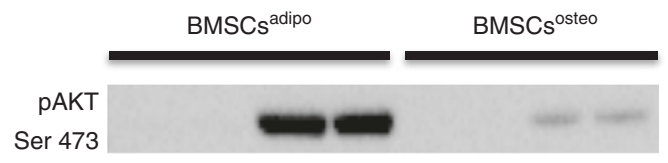

Total AKT

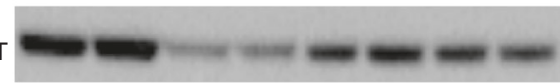

$\beta$-actin

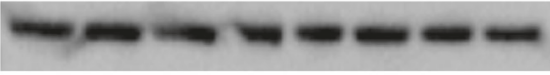

Pro-INSR $\beta$

INSR $\beta$

$100 \mathrm{nmol} \cdot \mathrm{L}^{-1}$ INS

C

${ }^{14} \mathrm{C}$ glucose uptake in undifferentiated cells

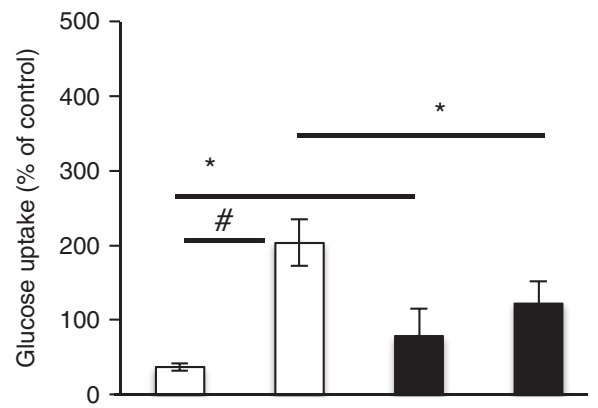

$100 \mathrm{nmol} \cdot \mathrm{L}^{-1}$ INS -

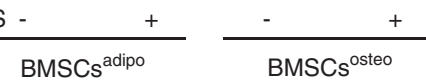

e

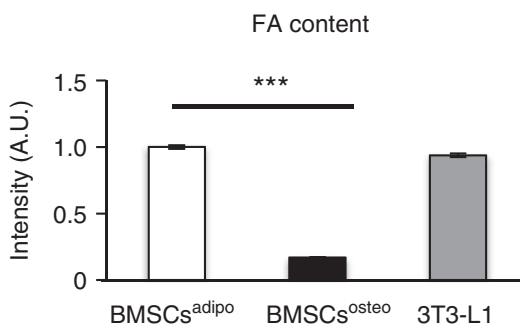

g

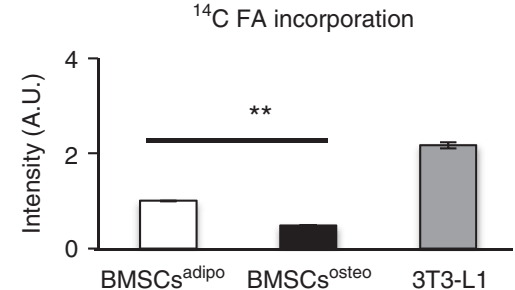

b

Differentiated cells in adipogenic condition

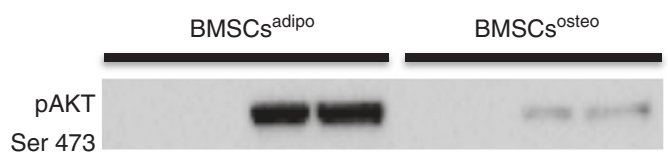

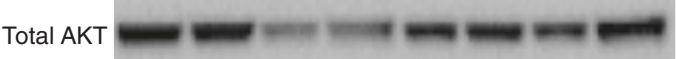

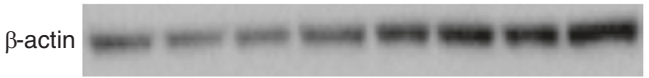

Pro-INSR $\beta$

INSR $\beta$

$100 \mathrm{nmol} \cdot \mathrm{L}^{-1} \mathrm{INS}$

d

${ }^{14} \mathrm{C}$ glucose uptake in differentiated cells in adipogenic condition

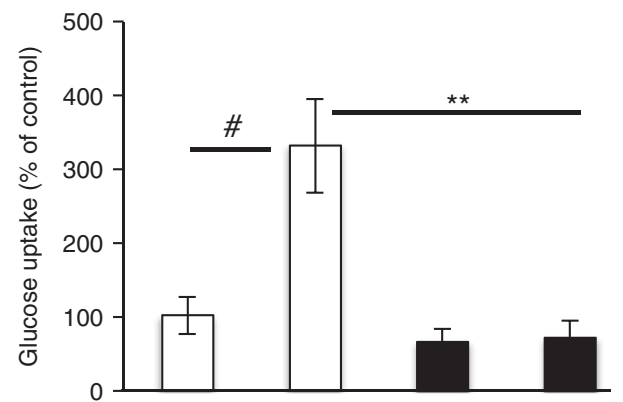

$100 \mathrm{nmol} \cdot \mathrm{L}^{-1}$ INS

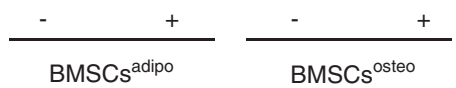

f

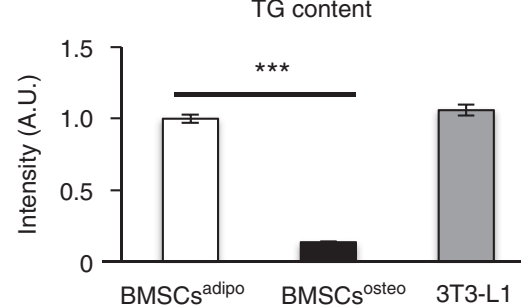

h

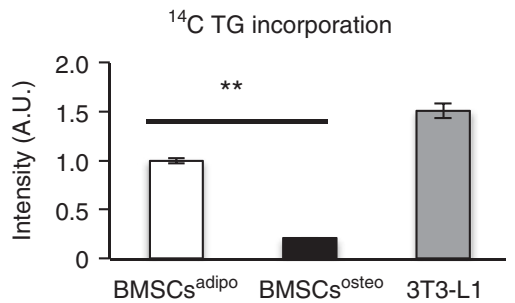

Fig. $2 \mathrm{BMSCs} \mathrm{s}^{\text {adipo }}$ and $\mathrm{BMSCs}{ }^{\text {osteo }}$ progenitors exhibit differential responses to insulin. Representative western blot to evaluate insulinstimulated (100 nmol. $\left.\mathrm{L}^{-1}, 15 \mathrm{~min}\right)$ phosphorylation of AKT (p-S473AKT) and total AKT, INSR $\beta$ a in undifferentiated BMSCs ${ }^{\text {adipo }}$ and BMSCs ${ }^{\text {osteo }}$ and $\mathbf{b}$ BMSCs ${ }^{\text {adipo }}$ and $\mathrm{BMSCs}^{\text {osteo }}$ differentiated cells in adipogenic conditions $(n=3)$. Insulin-stimulated glucose uptake using a ${ }^{14} \mathrm{C}$ glucose tracer after a 24-h incubation $\mathbf{c}$ in undifferentiated (baseline) BMSCs and $\mathbf{d}$ BMSCs differentiated under adipogenic conditions from BMSC ${ }^{\text {adipo }}$ and BMSCs ${ }^{\text {osteo }}$. Data are presented as the mean of glucose uptake normalized to the baseline of murine 3T3-L1 fibroblasts as a positive control \pm SEM from three independent experiments. ${ }^{*} P<0.05,{ }^{* *} P<0.01$ : BMSCs ${ }^{\text {adipo }}$ vs BMSCs ${ }^{\text {osteo, }}$, two-tailed unpaired Student's $t$ test; ${ }^{\#} P<$ 0.05: nonstimulated vs insulin-stimulated cells). Profile of neutral lipids in BMSCs adipo, BMSCs ${ }^{\text {osteo, }}$, and $3 T 3-\mathrm{L} 1$ cells under insulin stimulation $\left(100 \mathrm{nmol} \cdot \mathrm{L}^{-1}\right)$ using thin layer chromatography (TLC): e densitometry of triglycerides (TG) and $\mathbf{f}$ the the fatty acid (FA) content in BMSC differentiated cells under adipogenic conditions. Densitometry of ${ }^{14} \mathrm{C}$ FA (g) and ${ }^{14} \mathrm{C}$ TG (h) incorporation in BMSC differentiated cells under adipogenic conditions. Data are presented as the mean of F.C. \pm SEM from three independent experiments. $(n=3)\left({ }^{*} P<0.05,{ }^{*} P<0.01\right.$ : BMSCs $^{\text {adipo }}$ vs BMSCs ${ }^{\text {osteo }}$, one-way ANOVA) 
a

Glyco stress test

basal condition (D0)

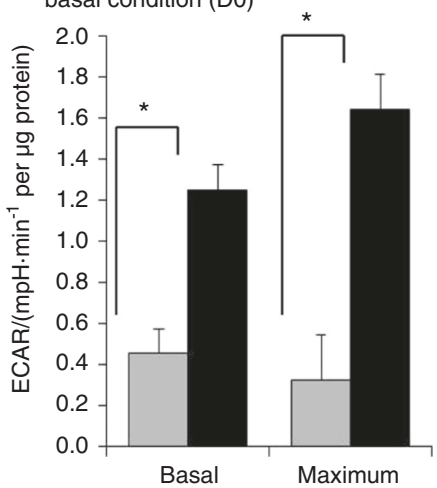

C

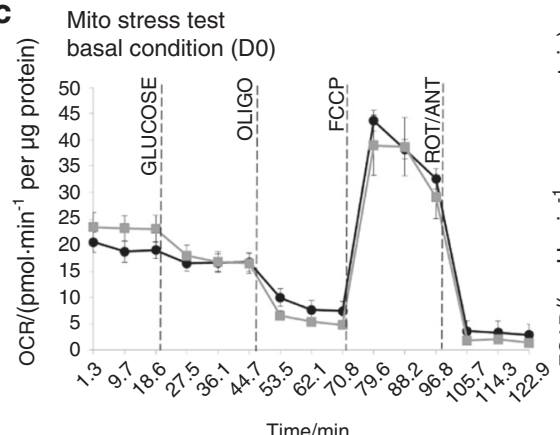

Time/min

d Mito stress test

adipogenic condition (D10)

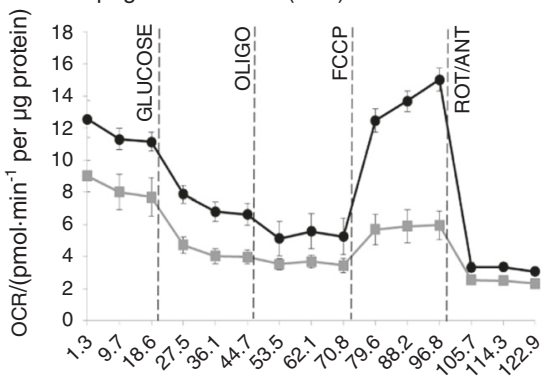

Time/min

e

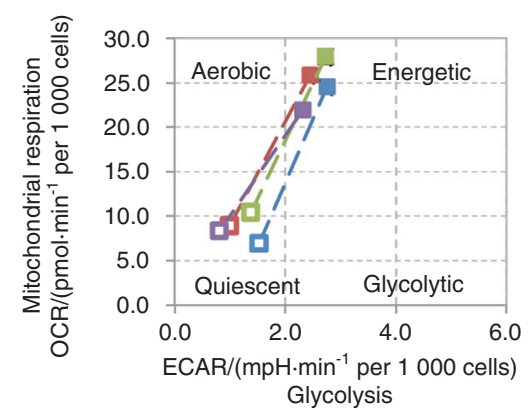

$\mathrm{BMSCs}^{\text {adipo }}$ Control (no ins) $\quad 6 \mathrm{~h}\left(1 \mu \mathrm{mol} \cdot \mathrm{L}^{-1} \mathrm{ins}\right)$

- $1 \mathrm{~h}\left(1 \mu \mathrm{mol} \cdot \mathrm{L}^{-1}\right.$ ins $)=24 \mathrm{~h}\left(1 \mu \mathrm{mol} \cdot \mathrm{L}^{-1}\right.$ ins $)$ b Glyco stress test adipogenic condition (D10)

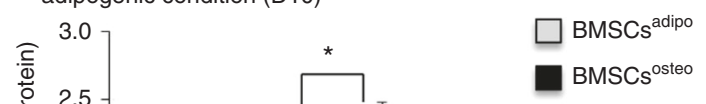

BMSCs $^{\text {osteo }}$
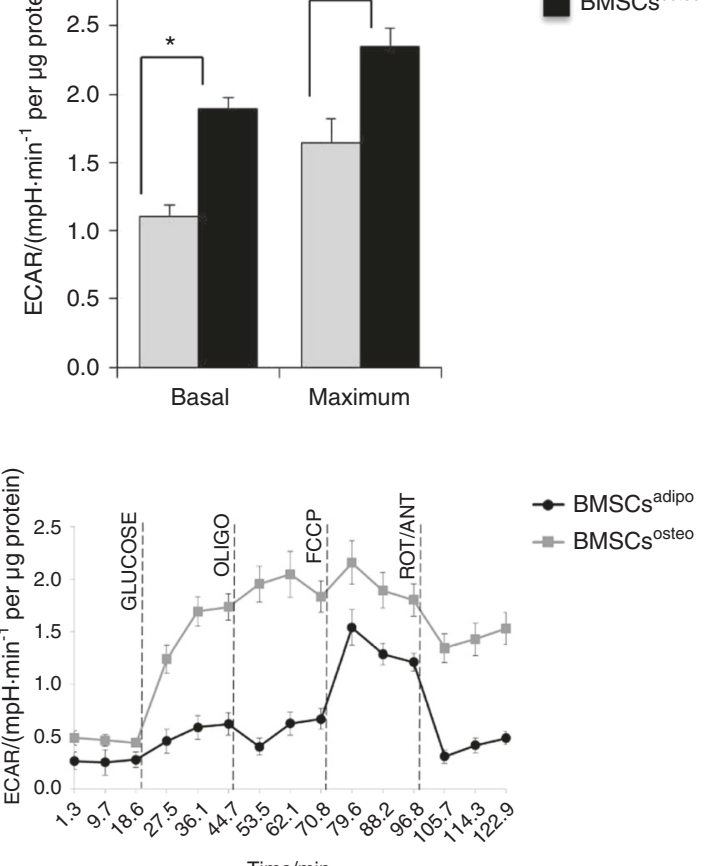

Time/min

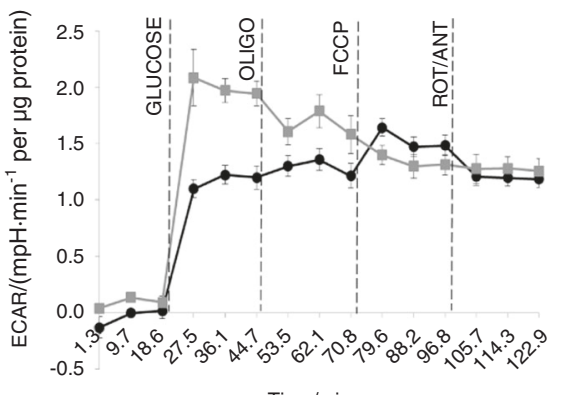

$$
\text { Time/min }
$$

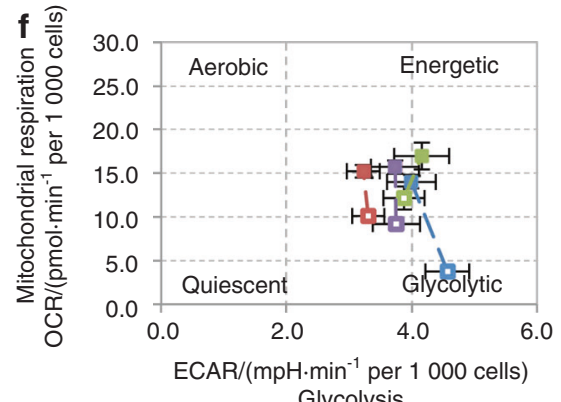

BMSCs ${ }^{\text {osteo }}$ Control (no ins) $6 \mathrm{~h}\left(1 \mu \mathrm{mol} \cdot \mathrm{L}^{-1}\right.$ ins $)$

- $1 \mathrm{~h}\left(1 \mu \mathrm{mol} \cdot \mathrm{L}^{-1}\right.$ ins $) \quad 24 \mathrm{~h}\left(1 \mu \mathrm{mol} \cdot \mathrm{L}^{-1} \mathrm{ins}\right)$

Fig. $3 \mathrm{BMSCs}^{\text {adipo }}$ and $\mathrm{BMSCs}^{\text {osteo }}$ exhibit a distinct bioenergetic profile defining their metabolic program. Bioenergetic profiling of $\mathrm{BMSCs}^{\text {adipo }}$ and $\mathrm{BMSCs}^{\text {osteo }}$ in basal (D0) and adipogenic conditions (D10) using Seahorse technology: $\mathbf{a}$, b in the glycolysis stress test measuring glycolytic function in cells; a basal and maximal glycolytic capacity in BMSCs ${ }^{\text {osteo }}$ compared with capacities in BMSCs ${ }^{\text {adipo }}$ in basal conditions (D0) and $\mathbf{b}$ adipogenic conditions (D10); $(n=3){ }^{*} P<0.05:$ BMSCs $^{\text {adipo }}$ vs BMSCs ${ }^{\text {osteo }}$. $\mathbf{c}$, d Bioenergetic profiling of undifferentiated and differentiated $\mathrm{BMSCs}^{\text {adipo }}$ and $\mathrm{BMSCs}^{\text {osteo }}$ in a Mito stress test measuring mitochondrial respiration in cells. $\mathbf{c}$ Representative graph of OCR and ECAR in media over time with a treatment of specific molecules (glucose - oligomycin (OLIGO) - carbonyl cyanide-4-(trifluoromethoxy) phenylhydrazone (FCCP) - rotenone/antimycin (ROT/ANT) corresponding to vertical line definition) in basal conditions (D0) and $\mathbf{d}$ adipogenic conditions; $(n=3){ }^{\#} P<0.05: \mathrm{BMSCs}^{\text {adipo }}$ vs BMSCs ${ }^{\text {osteo }}$ under adipogenic conditions (D10), two-tailed unpaired Student's $t$ test. e Acute effects of insulin $\left(1 \mu \mathrm{mol} \cdot \mathrm{L}^{-1}\right)$ on the metabolic phenotype of BMSCs${ }^{\text {adipo }}$ and $\mathbf{f} \mathrm{BMSCs}^{\text {osteo; }} ;(n=3)$ 
a

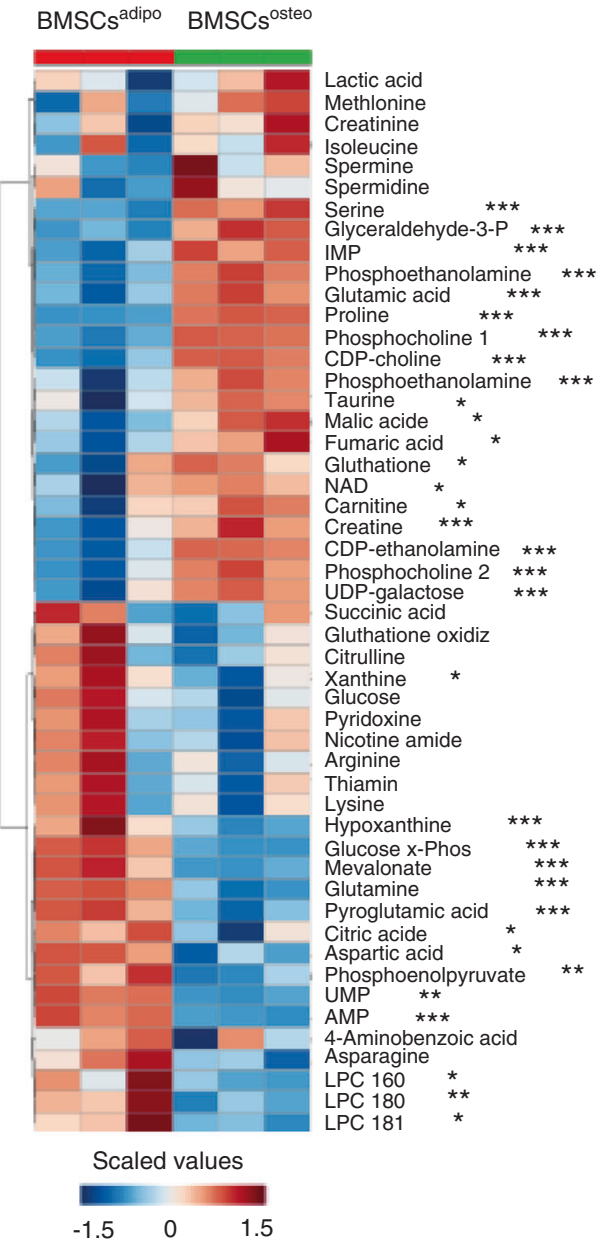

b
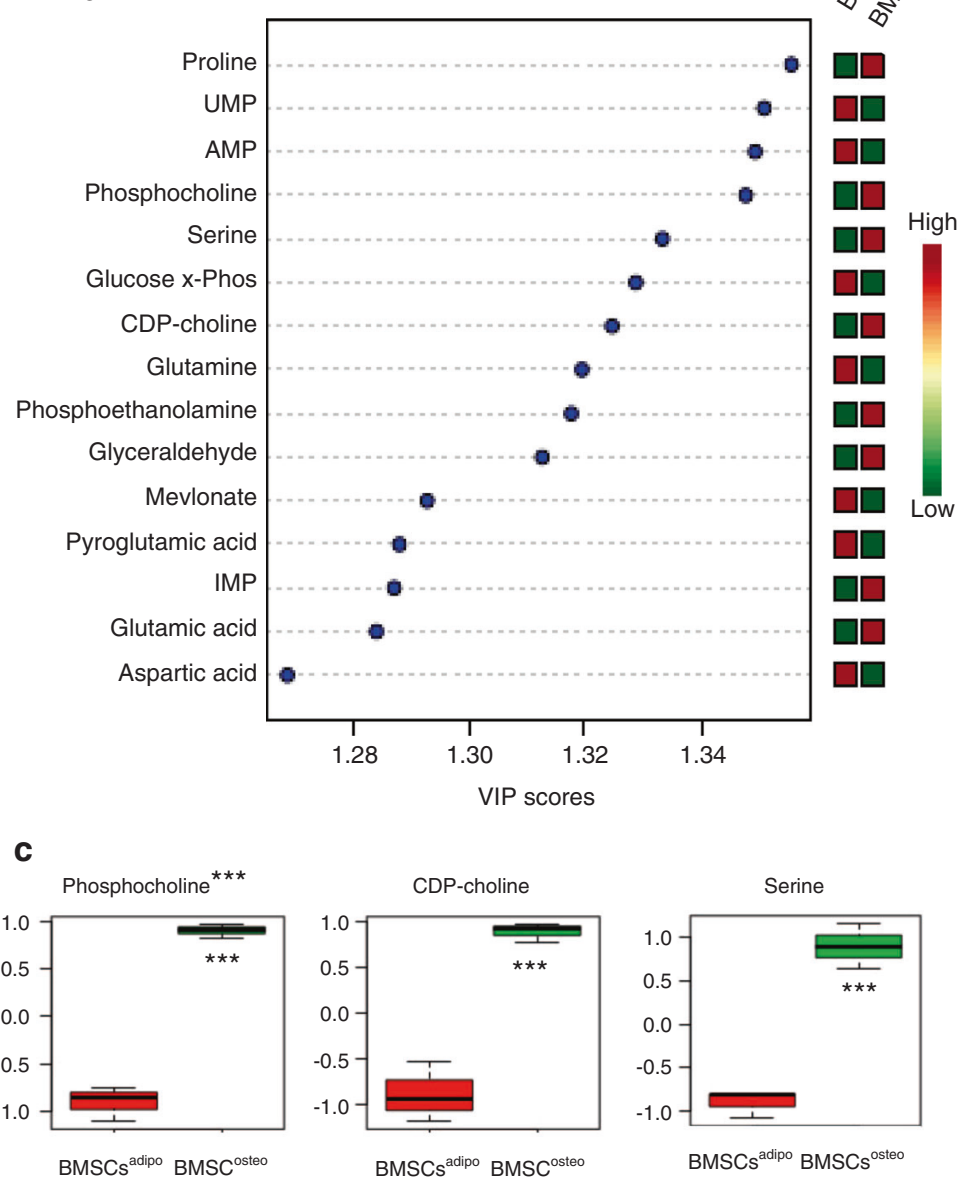
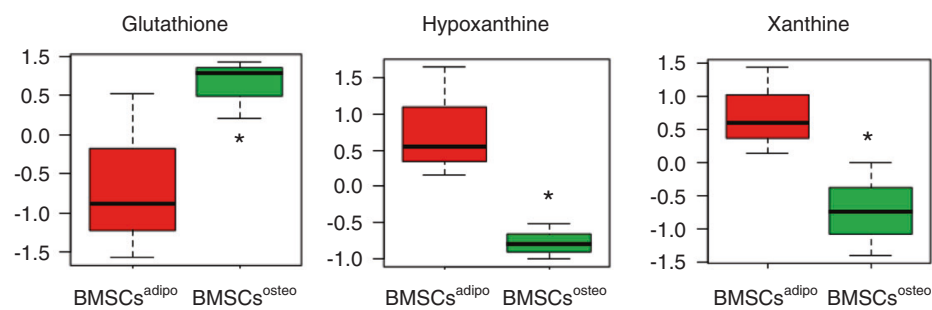

Fig. $4 \mathrm{BMSCs}^{\text {adipo }}$ and $\mathrm{BMSCs}^{\text {osteo }}$ exhibit significant differences in their metabolite composition. Global metabolic analyses of intracellular metabolites in basal conditions in $\mathrm{BMSCs}{ }^{\text {adipo }}$ and $\mathrm{BMSCs}^{\text {ssteo }}$ using liquid chromatography-mass spectrometry (LC-MS). a Heat map of all intracellular metabolites that are differentially expressed between BMSCs ${ }^{\text {adipo }}$ and BMSCs ${ }^{\text {osteo }}$ under basal conditions; $\mathbf{b}$ important features that are differentially expressed in BMSCs ${ }^{\text {adipo }}$ and BMSCs ${ }^{\text {osteo; }}$; metabolites differentially enriched in BMSCs ${ }^{\text {adipo }}$ versus BMSCs ${ }^{\text {osteo }}$ such as glycerophospholipids, especially phosphocholine and CPD-choline, glutathione, xanthine, and hypoxanthine. Data are presented as the mean \pm SEM from three independent experiments. $(n=3)\left({ }^{*} P<0.05,{ }^{* *} P<0.01,{ }^{* * *} P<0.001\right.$ : BMSCs ${ }^{\text {adipo }}$ vs BMSCs ${ }^{\text {osteo }}$, two-tailed unpaired Student's $t$ test)

CPD-choline, serine, and glutathione, which were enriched in $\mathrm{BMSCs}^{\text {osteo }}$ versus BMSCs ${ }^{\text {adipo }}$ (Fig. 4c). On the other hand, xanthine and hypoxanthine were more abundant in BMSCs ${ }^{\text {adipo }}$ compared with $\mathrm{BMSCs}^{\text {osteo, }}$, suggesting changes in membrane lipid content that affect intracellular signaling and the levels of reactive oxygen species. ${ }^{24}$ Additional metabolites that showed differences between the two immortalized cell lines included glyceraldehyde and glutamic acid, supporting the presence of higher glycolytic activity in BMSCs ${ }^{\text {osteo }}$. In addition, amino acid metabolites were different in $\mathrm{BMSCs}^{\text {adipo }}$ compared with $\mathrm{BMSCs}^{\text {osteo }}$, e.g., higher glutamine in $\mathrm{BMSCs}^{\text {adipo, }}$ which can serve as an alternative carbon source for OxPhos. $^{25}$
A similar distinct pattern of metabolites was identified in the metabolomic analysis of intracellular metabolites of BMSCs adipo and $\mathrm{BMSCs}^{\text {osteo }}$ following $24 \mathrm{~h}$ and $72 \mathrm{~h}$ of in vitro culture in basal conditions (Figs. S4 and S5), corroborating the presence of a stable metabolic program.

Is the metabolic program of BMSC progenitors flexible? Effects of parathyroid hormone (PTH) and inhibitors of insulin signaling and OxPhos

Our study demonstrated that committed adipocytic and osteoblastic cells exhibit a distinct metabolic program leading to differential responses under adipogenic culture conditions. 
However, it is not known whether these responses can be regulated by external cues. Thus, we studied the effects of treatment with PTH on AD differentiation when the cells were cultured under adipogenic culture conditions. PTH is known to enhance $\mathrm{OB}$ differentiation of progenitor cells through inducing changes in the bioenergetic profile. ${ }^{26}$ Gene expression profiling revealed that the expression level of PTH receptor 1 (Pth1r) was higher in BMSCs ${ }^{\text {osteo }}$ compared with the level in BMSCs adipo (Fig. 1k). In vitro treatment of BMSCs ${ }^{\text {adipo }}$ and BMSCs ${ }^{\text {osteo }}$ with PTH under adipogenic culture conditions for up to 10 days led to reduced $A D$ differentiation in $B M S C s^{\text {adipo, }}$, as evidenced by the decreased number of Nile Red-positive mature ADs and reduced expression levels of adipocytic genes (Ppary2 and Fsp27) (Fig. 5a, b). On the other hand, we observed increased expression of the PTH-responsive genes Bmp4, Igf1, and Igfr 1 in BMSCs ${ }^{\text {osteo }}$ but not in BMSCs ${ }^{\text {adipo }}$ (Fig. 5c). Furthermore, PTH treatment impaired insulin signaling accompanied by decreased Insr gene expression in BMSCs ${ }^{\text {adipo }}$ (Fig. 5d), which corroborates similar findings previously reported in 3T3-LI cells. ${ }^{27}$ In addition, PTH treatment altered the bioenergetic program of $\mathrm{BMSCs}^{\text {adipo, }}$, shifting the cells towards a more glycolytic state (Fig. 5e), as we observed increased "induced glycolysis" in the presence of PTH (PTH-treated versus Veh-treated cells, 22\%, $P<0.05$ ) (Fig. 5e, left graph). In addition, PTH treatment induced a shift toward more glycolytic ATP production, even though mitochondrial ATP production was also affected (Fig. 5e, right graph).

We also tested whether manipulation of insulin signaling in BMSCs adipo affects their differentiation state. Treatment of $\mathrm{BMSCs}^{\text {adipo }}$ with the INSR antagonist S961 (100 nmol. $\left.\mathrm{L}^{-1}\right)$ under adipogenic culture conditions for 10 days resulted in impaired $A D$ differentiation as evaluated by Nile Red staining (Fig. 6a), reduced gene expression of adipocytic genes (Ppary2, Fsp27, and Irs1) (Fig. 6b) and impaired insulin signaling as well as decreased Insr gene expression (Fig. 6c). S961 treatment changed basal metabolism in BMSCs ${ }^{\text {adipo }}$, as shown by a reduced glycolytic and enhanced OxPhos ATP production rate. In addition, based on ATP levels, S961 treatment increased ATP production in BMSCs ${ }^{\text {adipo }}$ to comparable levels as those observed in BMSCs ${ }^{\text {osteo }}$ (Fig. S6a). Finally, we tested whether inhibition of OxPhos in BMSCs adipo affects the differentiation capacity of cells. We treated BMSCs ${ }^{\text {adipo }}$ with oligomycin $\left(100 \mathrm{nmol} \cdot \mathrm{L}^{-1}\right.$ ) (an inhibitor of ATP-synthase, a key enzyme in mitochondrial respiration) for 10 days in the presence of adipogenic culture conditions. As shown in Fig. 6d, oligomycin treatment decreased the AD differentiation capacity as evidenced by a decreased number of mature ADs that were positive for Nile Red staining, decreased gene expression of adipocytic and insulin signaling-related genes (Ppary2, Fsp27, and Irs1) (Fig. 6e) and reduced insulin signaling along with decreased Insr gene expression (Fig. 6f). Moreover, oligomycin treatment exhibited modest effects on ATP production in BMSCs ${ }^{\text {adipo }}$ under basal undifferentiated culture conditions. However, under adipogenic induction, oligomycin significantly increased ATP production via glycolysis and reduced OxPhos (Fig. S6a, b).

Next, we examined the effect of $\mathbf{S 9 6 1}$ and oligomycin treatment on OB differentiation. 5961 did not exert additional effects on enhanced $\mathrm{OB}$ differentiation in $\mathrm{BMSCs}^{\text {osteo }}$ as determined by in vitro mineralized matrix formation, even though we observed a significant increase in the osteoblastic genes Alpl and Bmp2 (Fig. S6c). Oligomycin significantly inhibited OB differentiation of BMSCs ${ }^{\text {osteo, }}$ which was also accompanied by inhibition of cell proliferation following longer in vitro exposure (Fig. S6d).

Thus, these data demonstrate that targeting the metabolic program in BMSC progenitors modulates their differentiation capacity.

In vivo changes in the BM microenvironment induced by a HFD regulate $A D$ and $O B$ progenitor formation

To determine the physiological relevance of our findings, we employed the molecular signature of $\mathrm{BMSCs}^{\text {adipo }}$ to investigate the in vivo response of BMSC progenitors to the "obesogenic" environment present in C57BL/6 mice fed for 12 weeks with a HFD $(60 \% \text { fat })^{28}$ that resulted in obesity, hyperinsulinemia, and increased BM adiposity and AD size in the BM (Fig. S7a-C). In vitro cultures of BMSCs obtained from HFD-fed mice when compared with BMSCs obtained from mice on a normal diet (ND) exhibited a significant decrease in the number of BMSCs that are $\mathrm{CD} 73+$ and Sca+/CD140a+ and a concomitant increase in the expression of the adipocytic progenitor markers (mRNA and protein levels) CD80, CD141, CD53, and CD220 (Fig. 7a-C, Fig. S7d), which have previously been reported to be enriched in BMSCs adipo compared with BMSCs ${ }^{\text {osteo }}{ }^{21}$ (Fig. S7e). These findings were accompanied by upregulation of adipocytic gene markers (Ppary2, Clebpa, Fsp27, CD36, and Adipoq) and no changes in osteoblastic gene markers, suggesting expansion of BMSC AD progenitors (Fig. 7d). In addition, the colony forming unit-fibroblast (CFU-f) capacity of primary cultures of BMSCs was decreased in HFD-fed mice (Fig. S7f). Furthermore, exposing BMSCs obtained from HFD mice to adipogenic conditions in vitro led to increased AD differentiation (Fig. 7e), increased expression of adipocytic genes (Ppary2, Adipoq, Fsp27, and Lep) and no effect on OB differentiation (Fig. 7f). In addition, similar to our observations in BMSCs ${ }^{\text {adipo }}$, cultured BMSCs obtained from HFD mice revealed enhanced responsiveness to insulin compared with that of BMSCs obtained from ND mice (Fig. $7 \mathrm{~g}, \mathrm{~h}$ ). Thus, these data demonstrate the expansion of a population of adipocytic progenitors in BM following HFD-induced obesity that is similar in phenotype and functional responses to BMSCs adipo

\section{DISCUSSION}

In this study, we demonstrate that BMSC progenitors display a distinct metabolic program that determines their differentiation fate. $A D$ progenitors exhibit enhanced insulin signaling and $a$ higher capacity for OxPhos and lipid storage, whereas OB progenitors exhibit reduced insulin signaling, utilization of glycolytic activity to generate energy and an absence of lipid storage. We also demonstrate that targeting the AD progenitors' metabolic program can regulate the efficiency of differentiation. The physiological relevance of these findings was corroborated in vivo through an intervention model of HFD-induced obesity in mice that led to expansion and enhanced differentiation of adipocytic progenitors.

Cellular metabolic programing refers to the metabolic processes that not only provide energy for cellular homeostatic functions but also define the cellular phenotype by mediating changes in posttranslational modifications of histones and transcription factors. ${ }^{9}$ Their metabolites could participate in posttranslational modification of the genome by methylation of transcription factor promoters, which has been shown in muscle- or adipose-derived stem cells. ${ }^{9,29}$ Stem cells in different states of commitment have specific bioenergetic needs that are necessary for their functions; thus, their differentiation can be affected under different pathophysiological conditions related to the metabolic status of the organism. Changes in cellular metabolic programming have been reported to occur during the initial phases of somatic cell programming to pluripotent stem cells and during immune cell differentiation. $8,10,11$ However, limited information is available regarding the relationship between the metabolic phenotype and lineage-committed BMSC OB and AD progenitors.

Employing two functionally different murine progenitor cell lines of $A D$ progenitors $\left(B M S C s^{\text {adipo }}\right.$ ) and $O B$ progenitors $\left(\mathrm{BMSCs}^{\mathrm{osteo}}\right)$, we observed a distinct metabolic gene signature of $\mathrm{BMSCs}^{\text {adipo }}$ characterized by enrichment in genes of insulin signaling, autophagy, lipid metabolism, and glucose utilization, suggesting the presence of a hypermetabolic state. On the other hand, BMSCs ${ }^{\text {osteo }}$ were enriched in skeletal-associated genes and extracellular matrix genes that are relevant to their role in matrix 
a

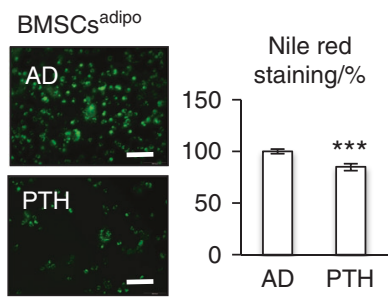

C

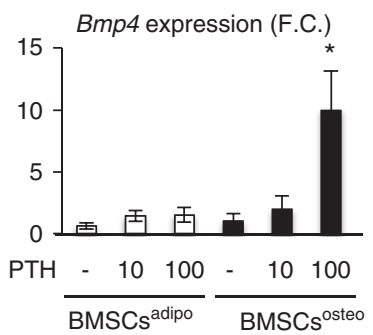

b
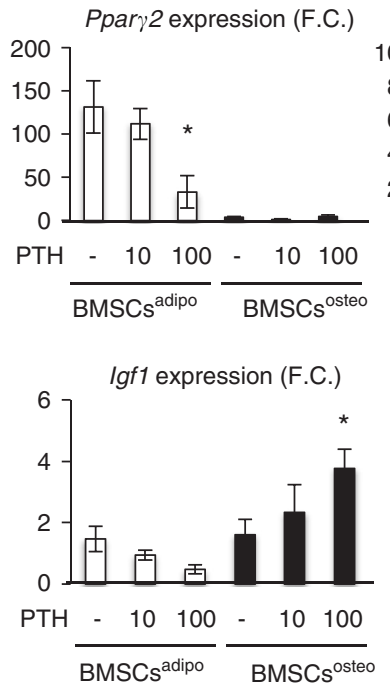

Fsp27 expression (F.C.)
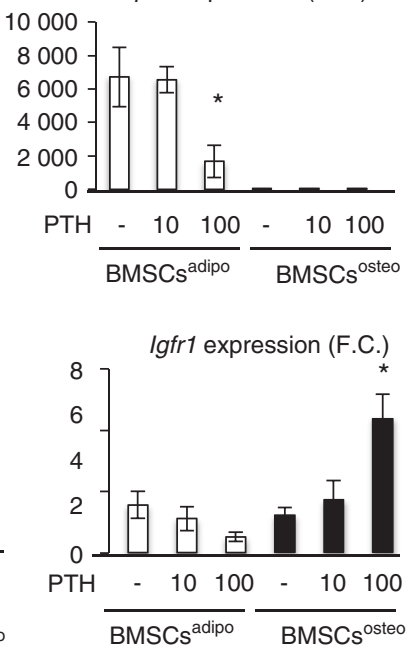

d
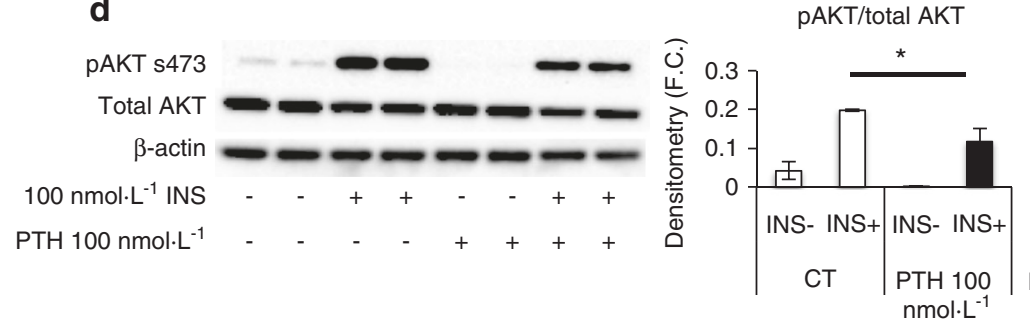

Insr expression (F.C.)

ATP production

e

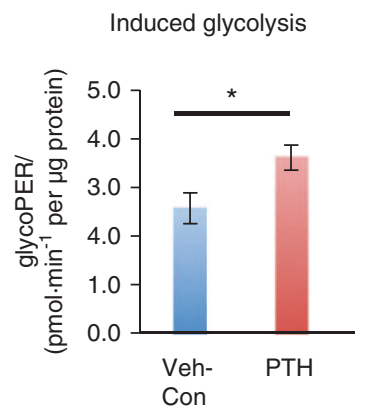

mito ATP production rate

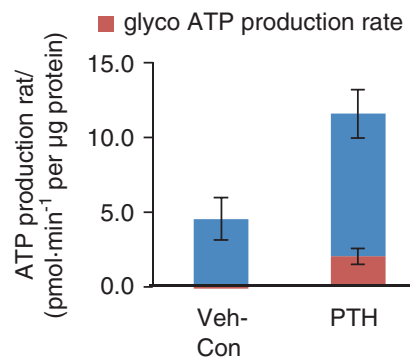

Fig. 5 PTH affects the adipogenic potential of $\mathrm{BMSCs}^{\text {adipo }}$ progenitors. Evaluation of PTH treatment on AD differentiation potential in $\mathrm{BMSCs}^{\text {adipo }}$ and $\mathrm{BMSCs} s^{\text {osteo }}$ a Representative pictures and evaluation of Nile Red staining in BMSCs adipo differentiated in adipogenic conditions (AD) and after chronic (D10) PTH treatment, (scale bar $100 \mu \mathrm{m}$ ); b gene expression of adipocytic and insulin signaling-related genes such as Ppary2, Fsp27, and Irs1 after chronic PTH treatment; c gene expression of PTH-responsive genes such as Bmp4, Igf1, and Igfr1 after chronic PTH treatment; data are presented as the mean of the fold change (F.C.) over undifferentiated cells \pm SEM, ( $n=3$ ) d representative western blot and densitometry of insulin-stimulated $\left(100 \mathrm{nmol} \cdot \mathrm{L}^{-1}, 15 \mathrm{~min}\right)$ phosphorylation of AKT (p-S473AKT) and total AKT and gene expression of Insr in BMSCs ${ }^{\text {adipo }}$ treated with PTH $100 \mathrm{nmol}^{-1} \mathrm{~L}^{-1} ;(n=3)$; e glycolytic potential of BMSCs ${ }^{\text {adipo }}$ and ATP production after $24 \mathrm{~h}$ of PTH treatment $(n=3)$; data are presented as the mean \pm SEM $\left({ }^{*} P<0.05,{ }^{* *} P<0.01\right.$; ${ }^{* * *} P<0.001:$ BMSCs $^{\text {adipo }}$ vs BMSCs ${ }^{\text {osteo }}$, two-tailed unpaired Student's $t$ test)

production and bone formation. This molecular phenotype suggests that BMSC progenitors mediate their differentiation functions in response to exogenous metabolic cues. These data corroborate recent findings from our group, reporting expansion of adipogenic progenitors in BMSC cultures of obese subjects along with enhanced insulin signaling. ${ }^{30}$

Progenitor cell clonal expansion requires the availability of a quick source of energy, and glycolysis is the preferred energy production mechanism, whereas the more energy efficient oxidative metabolism is associated with cell differentiation and mature functions. ${ }^{9}$ We observed a different metabolic pattern in BMSC progenitors. Committed osteoblastic progenitors employed glycolysis and, to a lesser degree, OxPhos, but committed adipocytic progenitors employed mainly OxPhos. This phenomenon has also been observed in undifferentiated versus differentiated pluripotent stem cells. ${ }^{31}$ The higher glycolytic profile of $\mathrm{BMSCs}^{\text {osteo }}$ represents a similarity with the stem cell state, while the higher OxPhos rate in BMSCs ${ }^{\text {adipo }}$ is associated with a more differentiated phenotype. It is plausible that glycolysis is preferred in committed osteoblastic cells because it is a source of rapid energy generation needed by the cells to respond quickly during bone regeneration following bone fracture or during bone remodeling. In addition, osteoblastic progenitors are present near the bone surface in a hypoxic microenvironment in which HIF1a is inducible and can drive the glycolytic processes. ${ }^{32,33}$ Our study corroborates the findings of a recent study by Guntur et al. ${ }^{34}$ 
a

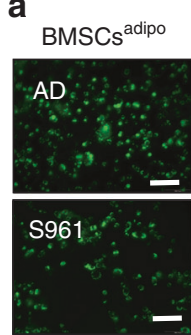

C

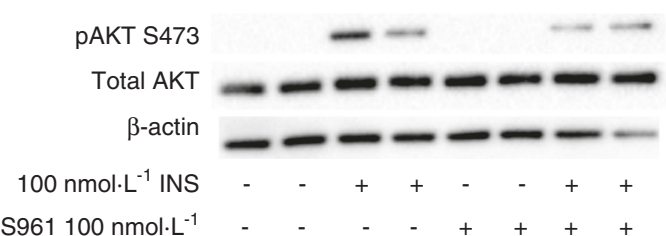

b Ppary2 expression (F.C.) Fsp27 expression (F.C.) Irs1 expression (F.C.)
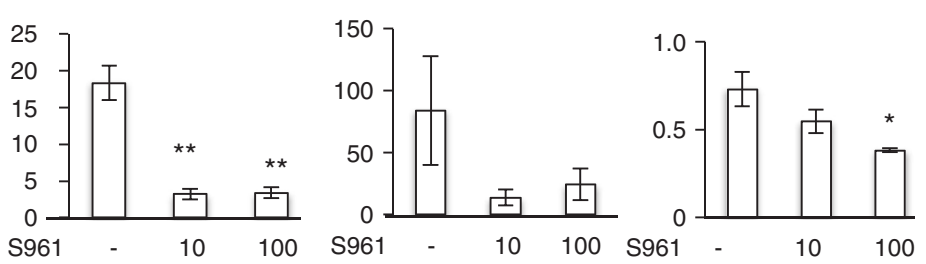

$\mathrm{pAKT} /$ total AKT

Insr expression (F.C.)
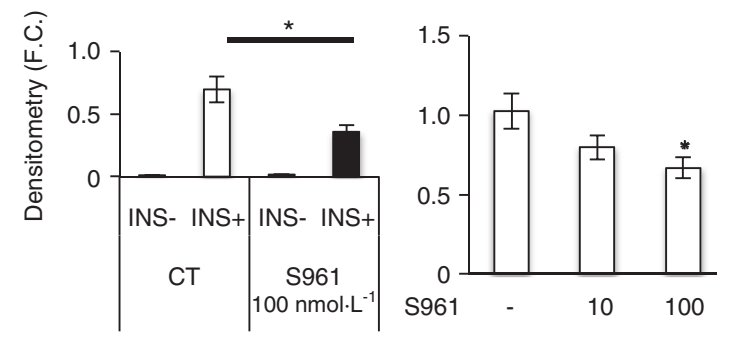

d

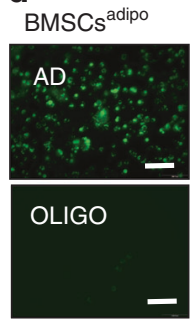

Nile red staining/\%

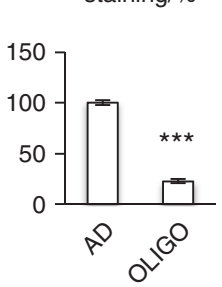

e

Ppar 2 2 expression (F.C.) $\quad$ Fsp27 expression (F.C.) Irs1 expression (F.C.)
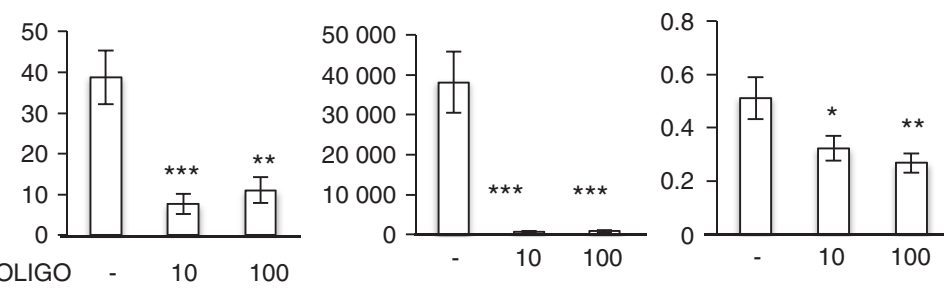

f
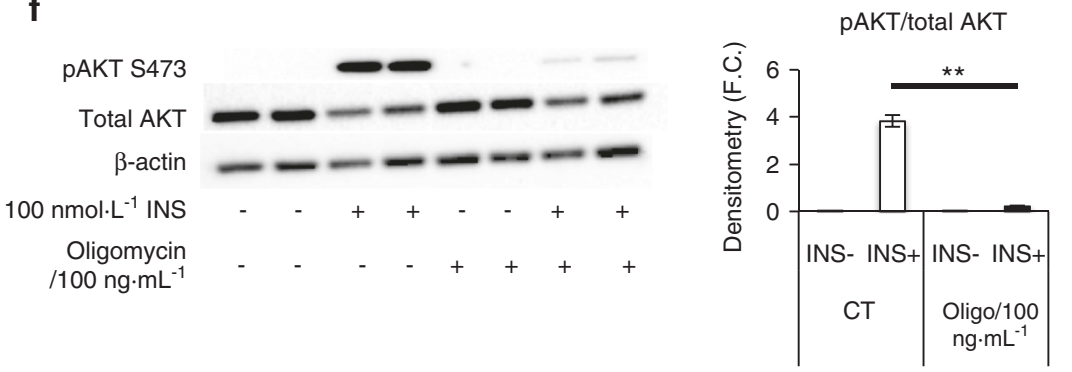

Insr expression (F.C.)

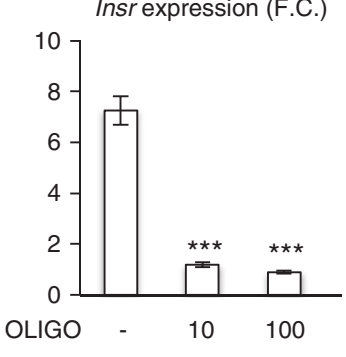

Fig. 6 Blocking insulin receptor signaling and oxidative phosphorylation affects the adipogenic potential of BMSCs adipo progenitors. a Representative pictures and evaluation of Nile Red staining in BMSCs ${ }^{\text {adipo }}$ differentiated in adipogenic conditions (AD) and after $100 \mathrm{nmol} \cdot \mathrm{L}^{-1} \mathrm{~S} 961$ (insulin receptor antagonist) treatment (D10), (scale bar $100 \mu \mathrm{m}$ ); b Gene expression of adipocytic and insulin signalingrelated genes such as Ppary2, Fsp27, and Irs1 after S961 treatment; data are presented as the mean of the fold change (F.C.) over undifferentiated cells \pm SEM, $(n=3) ;$ c representative western blot and densitometry of insulin-stimulated (100 nmol. $\mathrm{L}^{-1}$, $\left.15 \mathrm{~min}\right)$ phosphorylation of AKT (p-S473AKT) and total AKT and gene expression of Insr in BMSCs adipo treated with S961 $100 \mathrm{nmol} \cdot \mathrm{L}^{-1} ;(n=3)$; d representative pictures and evaluation of Nile Red staining in $\mathrm{BMSCs}^{\text {adipo }}$ differentiated in adipogenic conditions (AD) and after $100 \mathrm{ng}^{-1}$ oligomycin (inhibitor of ATP-synthase) treatment (D7), (scale bar $100 \mu \mathrm{m}$ ); e gene expression of adipocytic and insulin signaling-related genes such as Ppary2, Fsp27, and Irs1 after oligomycin treatment; data are presented as the mean fold change (F.C.) over undifferentiated cells \pm SEM, $(n=3)$; $\mathbf{f}$ representative western blot and densitometry of insulin-stimulated $\left(100 \mathrm{nmol} \cdot \mathrm{L}^{-1}, 15 \mathrm{~min}\right)$ phosphorylation of AKT (p-S473AKT) and total AKT and gene expression of Insr in BMSCs ${ }^{\text {adipo }}$ treated with oligomycin 10 and $100 \mathrm{ng}^{-\mathrm{mL}^{-1}} ;(n=2-3) ;\left({ }^{*} P<0.05,{ }^{* *} P<0.01 ;{ }^{* * *} P<0.001\right.$ : CT vs treated cells; two-tailed unpaired Student's $t$ test)

demonstrating that glycolysis is a major metabolic process during OB differentiation in a murine osteoblastic cell line MC3T3, in contrast to a committed preadipocytic cell line, 3T3-L1, which preferred OxPhos during AD differentiation. Thus, commitment to either OBs or ADs is associated with a characteristic bioenergetic profile that is maintained during differentiation.

Nutrient-sensitive signaling pathways (mTOR, AMPK, or insulin/ IGF-1) contribute to stem cell fate determination and energy fuel choice. ${ }^{35}$ Glucose is transported into the cells via glucose transporters (GLUT) that vary among different cell types. ${ }^{36}$ During skeletal development, glucose uptake is mediated primarily via GLUT1, which is insulin-independent. ${ }^{37}$ In our study, we observed that postnatal BM AD BMSCs ${ }^{\text {adipo }}$ progenitors expressed higher levels of insulin-responsive GLUT4 compared with BMSCs ${ }^{\text {osteo }}$, suggesting a higher responsiveness to insulin. This was further confirmed by the presence of enhanced insulin-stimulated glucose uptake in $A D$ progenitors and significant changes in the metabolic phenotype in response to the acute effect of insulin 
a

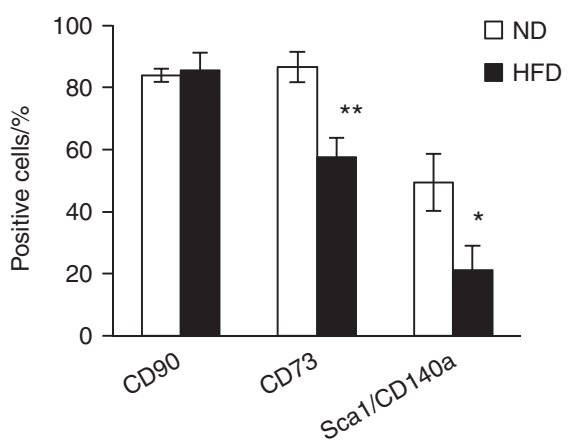

C

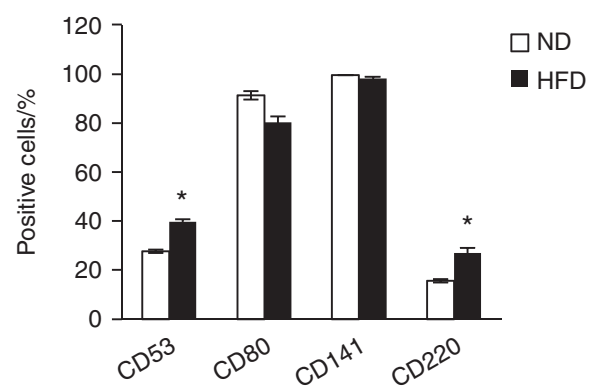

e
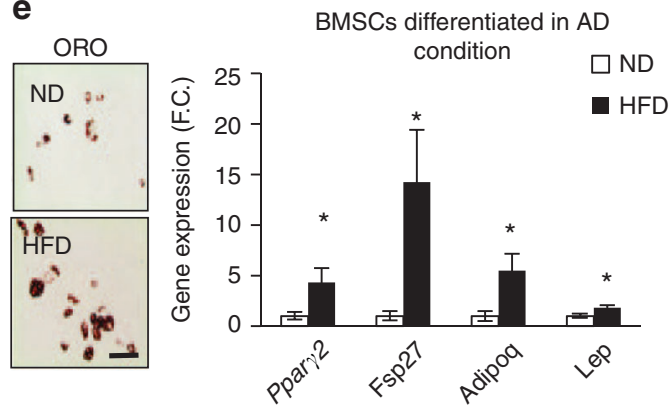

g

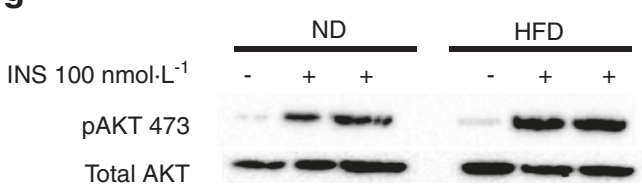

BMSCs in AD condition

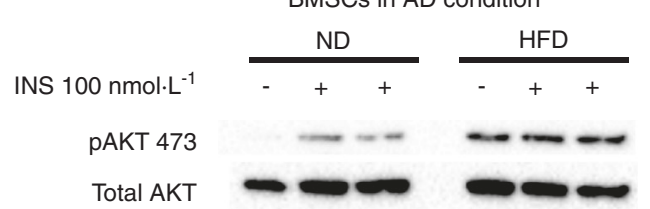

b

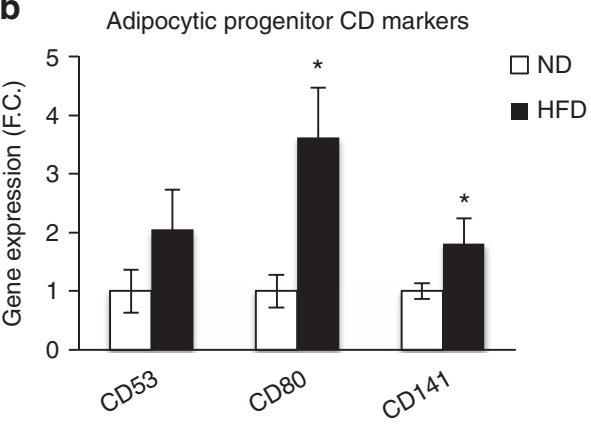

d

BMSCs undifferentiated

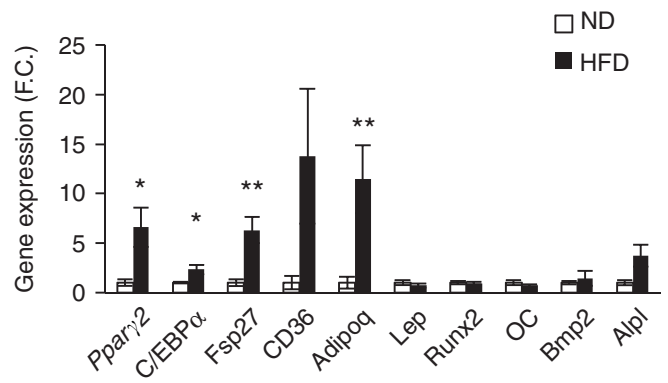

f

BMSCs differentiated in OB condition

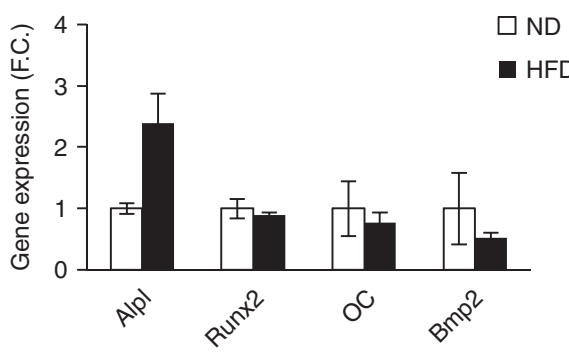

h

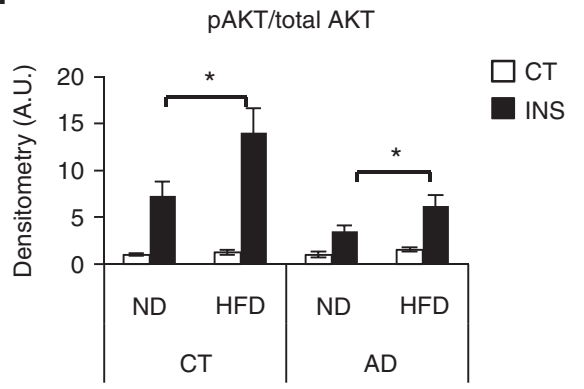

Fig. 7 In vivo changes in the bone marrow microenvironment induced by a high-fat diet (HFD) regulate adipocyte and osteoblast progenitors. a Screening of stem cell marker expression measured by flow cytometry in primary BMSCs isolated from mice fed with an ND or HFD for 12 weeks ( $n=5$ per group). b Gene expression of adipocytic progenitor CD markers (CD53, CD80, and CD141); and c flow cytometry of adipocytic CD markers (CD53, CD80, CD141, and CD220) in BMSCs obtained from ND and HFD mice ( $n=6$ per group). Data are presented as the mean of the fold change (F.C.) normalized to ND BMSC gene expression $\pm \mathrm{SEM}$; ${ }^{*} P<0.05$ : ND vs HFD, two-tailed unpaired Student's $t$ test. d Gene expression profile of adipocytic genes (Ppary2, Clebpa, Fsp27, CD36, Adipoq, and Lep) and osteoblastic genes (Runx2, OC, Bmp2, and Alpl) presented as the fold change in BMSCs of ND and HFD mice ( $n=6$ per group); e representative pictures of AD differentiation (day 10) visualized with Oil Red O staining in BMSCs from ND and HFD mice, (scale bar $100 \mu \mathrm{m}$ ) and gene expression profile of adipocytic genes (Ppary2, Fsp27, Adipoq, and Lep) presented as the fold change in AD differentiated BMSCs of ND and HFD mice ( $n=6$ per group); $\mathbf{f}$ gene expression profile of osteoblastic genes (Alpl, Runx2, OC, and Bmp2) presented as the fold change in OB differentiated BMSCs of ND and HFD mice ( $n=6$ per group); $g$ representative western blot of insulinstimulated $\left(100 \mathrm{nmol} \cdot \mathrm{L}^{-1}, 15 \mathrm{~min}\right)$ phosphorylation of AKT (p-S473AKT) and total AKT in undifferentiated and AD differentiated BMSCs isolated from ND and HFD mice ( $n=5-6$ per group); $\boldsymbol{h}$ densitometry of pAKT/total AKT in undifferentiated and AD differentiated BMSCs isolated from ND and HFD mice. Data are presented as the mean \pm SEM; ${ }^{*} P<0.05$, ${ }^{* *} P<0.01$ compared with ND, two-tailed unpaired Student's $t$ test 
when compared with $\mathrm{BMSCs}^{\text {osteo }}$. Our data corroborate and extend the results of Li et al. ${ }^{38}$ that different GLUT are utilized by murine bone cells depending on their developmental stage.

Is it possible to change lineage fate through targeting the metabolic program of BMSC committed progenitors? We observed that PTH treatment, inhibitors of insulin signaling and OxPhos affected the cellular metabolism of AD progenitors and inhibited their differentiation. Recent studies support the observed effects in our study. Fan et al. ${ }^{26}$ demonstrated that $\mathrm{PTH} / \mathrm{PTH} 1 \mathrm{r}$ signaling regulates BMSC cell fate and enhances OB lineage commitment. Similar to our findings, Esen et al. showed that PTH promotes OB differentiation by enhancing glycolysis, ${ }^{39}$ and Maridas et al. reported ${ }^{40}$ PTH-enhancing effects on BMAT lipolysis. Here, we also presented additional evidence that targeting insulin signaling or OxPhos can influence the differentiation fate of BMSC progenitors. While targeting insulin signaling in BMSC progenitors showed an opposite effect on $A D$ and $\mathrm{OB}$ differentiation, inhibition of OxPhos by a long exposure of oligomycin negatively affected both $\mathrm{BMSCs}^{\text {adipo }}$ and $\mathrm{BMSCs}^{\text {osteo }}$ progenitors during differentiation. However, further studies are needed to investigate whether acute treatment with oligomycin exhibits a similar effect. As previously shown by Kim et al. ${ }^{41}$ and Guntur et al., ${ }^{34}$ OBs may use OxPhos during their differentiation, and depending on the source of fuel, either FA or glucose, this was stimulated or inhibited.

Our findings suggest that BMSC progenitors exhibit a metabolic program upstream of differentiation and not, as commonly assumed, that as progenitors differentiate, they acquire changes in their metabolic program. This difference is important in clarifying the role of BM ADs in whole body energy metabolism and bone homeostasis.

An inverse relationship between BMAT and bone mass has been observed in several studies. However, analysis of the published data shows that in many situations, BMAT and bone mass can change independently. ${ }^{7}$ Our study provides a cellular explanation for these differences, as it demonstrates the presence of $A D$ and $O B$ progenitors within the $B M$ microenvironment that respond differently to external stimuli as well as to the metabolic status of the organism. In hyperinsulinemic, hyperglycemic, and hyperlipidemic conditions using HFD-fed mice, we and others ${ }^{42}$ showed expansion of adipocytic progenitors in the BM microenvironment. In addition, our data advance the concept that osteoblastic and adipocytic mature cell formation can be regulated not only at the level of stem cells but also at the level of committed progenitors. For translational medicine, manipulation of metabolic pathways in BMSC progenitors is a plausible approach to enhance lineagespecific differentiation and tissue regeneration.

\section{MATERIALS AND METHODS}

Cell culture of MSC clonal cell lines (BMSCs ${ }^{\text {adipo }}$ and $\mathrm{BMSCs}^{\text {osteo }}$ ) The murine BM-derived spontaneously immortalized clonal cell lines $\mathrm{BMSCs}^{\text {adipo }}$ and BMSCs ${ }^{\text {osteo }}$ were established and characterized previously in our laboratory (for more information, see papers ${ }^{19,20}$ ). For expansion, both cell lines were cultivated in basal DMEM supplemented with $10 \%$ fetal bovine serum (FBS; Gibco Invitrogen, USA) and $100 \mu \mathrm{g} \cdot \mathrm{mL}^{-1}$ streptomycin and $100 \mathrm{U} \cdot \mathrm{mL}^{-1}$ penicillin.

Microarray analyses

$\mathrm{BMSCs}^{\text {adipo }}$ and $\mathrm{BMSCs}^{\text {osteo }}$ were cultured under standard culture conditions as described above. Total RNA was isolated at day 0 to perform global gene expression analysis using Affymetrix GeneChip ${ }^{\circledR}$ MG430A 2.0 Arrays (Affymetrix, USA) (GEO accession number: GSE124905). These data were published in a previous publication by Taipaleenmäki et al. ${ }^{20}$ We performed addition analyses to compare global gene expression in basal conditions to determine the GO categories of the genes that were differentially expressed between $\mathrm{BMSCs}^{\text {adipo }}$ and $\mathrm{BMSCs}^{\text {osteo }}$ (Fig. $1 \mathrm{~b}$ and Fig. S1).

\section{$A D$ differentiation}

For in vitro $A D$ differentiation, the cells from both cell lines were seeded at a density of 20000 cells $\mathrm{cm}^{-2}$ and incubated in DMEM supplemented with $9 \%$ horse serum and ADinduction medium containing $3 \mu \mathrm{g} \cdot \mathrm{mL}^{-1}$ insulin (Sigma), $1 \times 10^{-6} \mathrm{~mol} \cdot \mathrm{L}^{-1}$ dexamethasone, and $0.5 \mu \mathrm{mol} \cdot \mathrm{L}^{-1}$ 3-isobutyl-1-methylxanthine (IBMX; Sigma). The medium was changed every second day for 10 days. The ADs were visualized by Oil Red $\mathrm{O}$ staining.

\section{Oil Red O staining}

Cells were fixed in $4 \%$ paraformaldehyde for $10 \mathrm{~min}$ at room temperature (RT) and then stained with Oil Red O (Sigma-Aldrich) to visualize the lipid content. Briefly, cells were rinsed in $3 \%$ isopropanol solution and stained with filtered Oil Red O solution ( $0.5 \mathrm{~g}$ in $100 \%$ isopropanol) for $1 \mathrm{~h}$ at RT.

Nile red staining

Nile red fluorescence quantification of adipogenesis was performed using a stock solution of Nile red $\left(1 \mathrm{mg} \cdot \mathrm{mL}^{-1}\right)$ in DMSO. Staining was performed on unfixed cells. Cultured differentiated cells were grown in polystyrene flat-bottom 96-well tissue culture (TC)-treated black microplates and washed once with PBS. The dye was directly added to the cells $\left(5 \mu \mathrm{g} \cdot \mathrm{mL}^{-1}\right.$ in PBS) and incubated for $10 \mathrm{~min}$ at RT, and then the cells were washed twice with PBS. The fluorescence intensity was measured using a microplate reader with the bottom well-scan mode, during which nine readings were taken per well using excitation $(485 \mathrm{~nm})$ and emission $(572 \mathrm{~nm})$ spectra.

\section{OB differentiation}

The cells were plated at a density of $20000 \mathrm{cells} \cdot \mathrm{cm}^{-2}$ in alpha MEM medium (Gibco) containing $10 \% \mathrm{FBS}, 100 \mathrm{U} \cdot \mathrm{mL}^{-1}$ penicillin (Gibco), $100 \mathrm{~g} \cdot \mathrm{mL}^{-1}$ streptomycin (Gibco). One day after seeding, the medium was replaced with $\mathrm{OB}$ induction medium composed of base medium supplemented with $10 \mathrm{mmol} \cdot \mathrm{L}^{-1}$ B-glycerophosphate (Sigma-Aldrich), $10 \mathrm{nmol} \cdot \mathrm{L}^{-1}$ dexamethasone (Sigma-Aldrich) and $50 \mu \mathrm{g} \cdot \mathrm{mL}^{-1}$ vitamin $\mathrm{C}$ (Sigma-Aldrich). The medium was changed every other day for 10 days.

ALP activity assay

Cells were incubated with naphthol AS-TR phosphate solution containing Fast Red TR (Sigma-Aldrich) as described previously. ${ }^{43}$ ALP activity was measured using p-nitrophenyl phosphate (Fluka Chemie) as the substrate. ${ }^{44}$

Quantitative real-time PCR (qRT-PCR)

Total RNA was extracted from the cells using TRIzol (Invitrogen) following the manufacturer's protocol. The RNA concentration was measured using a Nanodrop 2100, and cDNA synthesis was performed from $1 \mu \mathrm{g}$ of total RNA using a commercial revertAid $\mathrm{H}$ minus first strand CDNA synthesis kit (Fermentas, Helsingborg, Sweden) according to the manufacturer's instructions. Gene expression was analyzed by qRT-PCR using IQ SYBR Green Master Mix with the ABI Step One Plus Real-Time PCR System (Applied Biosystems) according to the manufacturer's instructions. A list of primers used is given in Table S1. qPCR data were normalized to the housekeeping gene 36B4 expression and calculated using the formula $2^{-(\Delta \Delta \mathrm{Ct})}$ in which $\Delta \Delta \mathrm{Ct}=(\mathrm{Ct} \text { mRNA }-\mathrm{Ct} 36 \mathrm{~B} 4)_{\text {sample }}-(\mathrm{Ct}$ mRNA - Ct 36B4) control sample.

Western blot analyses

Cell lysates were prepared using RIPA lysis buffer. Protein concentrations were measured using the BCA assay (Thermo Fisher). Thirty micrograms of protein was separated on $8 \%-12 \%$ NuPAGE Novex Bis-Tris gels (Invitrogen) followed by transfer to a 
polyvinylidene fluoride membrane (Millipore A/S). Antibodies against the INSR and total or Ser-473 phosphorylated AKT (pAKT) were obtained from Cell Signaling Technology (Herlev, Denmark). Anti- $\beta$-actin was purchased from Santa Cruz Biotechnology, Inc. (Aarhus, Denmark). Quantification of western blots was performed with Bio-Rad software.

\section{Glucose uptake}

Glucose uptake was measured using [1,2-3H]-2-deoxy-D-glucose as previously described. ${ }^{45}$ The cells were starved $4 \mathrm{~h}$ before the assay in basal medium without serum (DMEM/0.5\% BSA). Then, the cells were incubated in basal DMEM/0.5\% BSA containing [1,2$3 \mathrm{H}]$-2-deoxy-D-glucose in the presence or absence of $100 \mathrm{nmol} \cdot \mathrm{L}^{-1}$ insulin (Sigma) for $4 \mathrm{~h}$ and $24 \mathrm{~h}$. Next, the cells were washed and scraped in PBS buffer, and neutral lipids were separated by TLC. The scintillation counts in cell lysates were measured on a scintillator (PerkinElmer). The results were normalized to protein concentrations and presented as a fold change \pm SEM.

Lipid extraction and TLC

Lipids were extracted using Bligh and Dyer extraction of total lipids from mammalian cells by adding chloroform:methanol (1:1) solution followed by a solution of chloroform: $0.2 \mathrm{~mol} \cdot \mathrm{L}^{-1} \mathrm{KCl}$, which resulted in phase separation of the organic and aqueous phases. The organic phase was removed and dried under nitrogen and then resuspended in chloroform:methanol. A 20$\mu \mathrm{L}$ aliquot was used for scintillation measurements. The rest of the samples were loaded in duplicate, and TLC plates were developed to the top of the plate in the solvent system hexane: diethylether:acetic acid (80:30:1). Lipids were visualized after spraying the plate with $10 \% \mathrm{CuSO}_{4}$ dissolved in $8 \% \mathrm{H}_{2} \mathrm{PO}_{4}$ and incubating in a $180{ }^{\circ} \mathrm{C}$ oven. For radioactive lipid spot visualization, the plates were placed in cassettes (storage radioactive screen) for 1 month in the dark and then the storage screen was scanned on The Typhoon Scanner. Representative scan pictures are presented as a PDF.

Bioenergetic analyses/profiling

$\mathrm{BMSCs}^{\text {adipo }}$ and BMSCs ${ }^{\text {osteo }}$ murine cell lines were seeded in 24well multiwell plates (Seahorse Bioscience) and differentiated as described above. OCRs of nondifferentiated and 10-daydifferentiated cells were determined using an XF24 Extracellular Flux Analyzer (Seahorse Bioscience). Glycolytic stress tests were performed by sequentially adding $10 \mathrm{mmol} \cdot \mathrm{L}^{-1}$ glucose (and $100 \mathrm{nmol} \cdot \mathrm{L}^{-1}$ insulin), rotenone and antimycin A (Rot/Ant; $1 \mu \mathrm{mol} \cdot \mathrm{L}^{-1}$ each), carbonyl cyanide-4-(trifuoromethoxy)phenylhydrazone (FCCP; $2 \mu \mathrm{mol} \cdot \mathrm{L}^{-1}$ ), followed by 2-deoxyglucose $\left(50 \mathrm{mmol} \cdot \mathrm{L}^{-1}\right)$. Conversely, a mitochondrial stress test was performed by adding $10 \mathrm{mmol} \cdot \mathrm{L}^{-1}$ glucose (and $100 \mathrm{nmol} \cdot \mathrm{L}^{-1}$ insulin), oligomycin A (Oligo; $\left.2 \mu \mathrm{mol} \cdot \mathrm{L}^{-1}\right), \mathrm{FCCP}\left(2 \mu \mathrm{mol} \cdot \mathrm{L}^{-1}\right)$, and Rot/Ant ( $1 \mu \mathrm{mol} \cdot \mathrm{L}^{-1}$ each) in succession. The basal OCR was then calculated by subtracting Rot/Ant from the unstimulated OCR value. Maximal respiration was determined following FCCP treatment according to $\mathrm{Wu}$ et al. ${ }^{46}$ The ATP production rate was measured by an ATP rate assay, and the acute effects of insulin were measured by an energy phenotype test (Agilent Technologies). Data are presented as normalized to $\mu \mathrm{g}$ protein.

Metabolomics measured by LC-MC

Sample analysis was carried out by MS-Omics as follows. Intracellular extracts were dried under nitrogen flow and reconstituted in a MilliQ water/acetonitrile (1:1) mixture. Extracellular supernatants were diluted $1: 3$ in MilliQ water before acetonitrile was added (1:1). The analysis was carried out using a UPLC system (UPLC Acquity, Waters) coupled with a time of flight mass spectrometer (Xevo G2 Tof, Waters). An electrospray ionization interface was used as the ionization source. Analysis was performed in negative and positive ionization mode. The
UPLC was performed using a slightly modified version of the protocol described by Paglia et al. ${ }^{47}$ Data processing was carried out using MZmine $2^{48}$ followed by curation using a custom made in-house protocol. The compounds were identified using both peak retention times (compared with authentic standards) and accurate mass (with an accepted deviation of $0.005 \mathrm{Da}$ ). Metabolomic data were analyzed using MetaboAnalyst software (www. metaboanalyst.ca).

Treatment of BMSC progenitors with S961, PTH, and oligomycin $\mathrm{BMSCs}^{\text {adipo }}$ and $\mathrm{BMSCs}^{\text {osteo }}$ were treated during their adipogenic differentiation protocol with different reagents to test their effect on differentiation: INSR antagonist $10 \mathrm{nmol} \cdot \mathrm{L}^{-1}$ or $100 \mathrm{nmol} \cdot \mathrm{L}^{-1}$ to block insulin signaling as one of the differently activated signaling pathways between cell lines (S961; cat. no. ABIN2876379) (www. antibodies-online.com), PTH known to enhance OB differentiation (1-34 fragment bovine) (Sigma; cat. no. P3671) $10 \mathrm{nmol} \cdot \mathrm{L}^{-1}$ or $100 \mathrm{nmol} \cdot \mathrm{L}^{-1}$, and oligomycin $10 \mathrm{nmol} \cdot \mathrm{L}^{-1}$ or $100 \mathrm{nmol} \cdot \mathrm{L}^{-1}$, an inhibitor of OxPhos (Sigma, cat. no. 75351) (in independent experiments) for 10 days. The AD differentiated cells were harvested after 10 days for subsequent analyses. The treatments with PTH, S961 and oligomycin were tested on mouse BMSCs (mBMSCs) (Fig. S8).

Animal work

Male C57BL/6J mice (Taconic) were given ad libitum normal chow diet (Altromin ${ }^{\circledast}$ 132003; containing 6\% fat, 30\% protein, 63\% carbohydrate, and $7.7 \%$ sucrose) or $60 \mathrm{kcal} \%$ HFD (Research Diet D12492; containing $35 \%$ fat, $26 \%$ protein, $26 \%$ carbohydrate, and $8.8 \%$ sucrose) at 8 weeks of age for a period of 12 weeks. Animals were bred and housed under standard conditions $\left(21^{\circ} \mathrm{C}, 55 \%\right.$ relative humidity) on a 12-h light/12-h dark cycle. All experimental procedures were approved by the Danish Animal Ethical Committee (2017-15-0201-01210).

Glucose metabolic studies

A glucose tolerance test (GTT) was performed after 12 weeks of HFD. For GTT, overnight-fasted mice were injected with $1 \mathrm{~g} \cdot \mathrm{kg}^{-1}$ D-glucose i.p. and glucose levels were measured at different timepoints using a BREEZE ${ }^{\circledR} 2$ meter (Bayer).

Isolation of BMSCs

BMSCs were isolated from the bones of the front and hind limbs of C57BL/6J male mice (after 12 weeks of HFD) according to the paper by Tencerova et al. $^{28}$ following the steps of bone crushing, collagenase digestion, and negative selection of CD45, CD31, and Ter1 19 cells using microbeads (Miltenyi) according to the protocol of Zhu et al. and Houlihan et al. ${ }^{49,50}$ Isolated BMSCs were cultured in vitro, passaged, and used for subsequent analyses.

\section{CFU assay}

For assessment of CFUs, cells were plated at a density of 500 cells in a $60-\mathrm{mm}$ culture dish. After 14 days, colonies displaying more than 50 cells were counted using crystal violet staining (SigmaAldrich).

\section{Flow cytometry}

Immunophenotyping of BMSCs was performed by flow cytometry. Adherent cells were removed from flasks using $0.05 \%$ trypsin EDTA and incubated with Fc-mouse blocking reagent followed by preconjugated antibodies for isotype controls and specific markers (rat anti-mouse Sca-1-PE, cat. no. 553336; rat anti-mouse CD140a-APC, cat. no. 562777; rat anti-mouse CD73-PE, cat. no. 550741; BD Biosciences and rat anti-mouse CD105-PE, cat. no. 120408; rat anti-mouse CD90.2-PE, cat. no. 140307; rat anti-mouse CD44-PE, cat. no. 103024; BioLegend; rat anti-mouse CD53-FITC, cat. no. 124705, BioLegend; Armenian hamster anti-mouse CD80 BV421, cat. no. 104725; BioLegend; rat anti-mouse CD134-APC, cat. 
no. 119413 , BioLegend; rat anti-mouse CD141-PE, cat. no. 566338, BD Bioscience, goat anti-mouse CD220-PE, cat. no. FAB1544P, R\&D Biosystems) used according to the manufacturers' recommendations. The flow cytometry was performed by a BD FACSAria II (BD Biosciences) and analyzed by FlowLogic analysis software.

Statistical analysis

The statistical significance of the differences in the means of the investigated cell lines was determined by unpaired Student's $t$ test or one-way ANOVA where appropriate using GraphPad Prism v $6.0 \mathrm{c}$ software. For all tests, $P \leq 0.05$ was considered significant. The data are presented as the means \pm SEM.

\section{ACKNOWLEDGEMENTS}

The authors are grateful to Tina Kamilla Nielsen for her excellent technical assistance. We thank Lea G. Johnsen from MS-OMICS Copenhagen for her excellent work in metabolomics analyses. This work was supported by a fellowship grant from the Danish Diabetes Academy supported by the Novo Nordisk Foundation (MT) and the Novo Nordisk Foundation (MK, NNF15OC0016284) and a research grant from the Odense University Hospital (R29-A1374).

\section{AUTHOR CONTRIBUTIONS}

MT and MK conceived the project. MT, ERR, and DNP performed the in vitro experiments and collected and analyzed the data. ERR and CJR performed and helped with the interpretation of bioenergetic profiling results. MD performed and helped with the interpretation of metabolomics data. DN and NF helped with glucose uptake, TLC experiments and their interpretation. FF and DA contributed to collecting HFD mouse data. AH performed microarray biostatistical analyses. MT and MK designed and supervised the study and wrote the paper. All authors revised and approved the paper.

\section{ADDITIONAL INFORMATION}

The online version of this article (https://doi.org/10.1038/s41413-019-0076-5) contains supplementary material, which is available to authorized users.

Competing interests: The authors declare no competing interests.

\section{REFERENCES}

1. Rosen, C. J., Ackert-Bicknell, C., Rodriguez, J. P. \& Pino, A. M. Marrow fat and the bone microenvironment: developmental, functional, and pathological implications. Crit. Rev. Eukaryot. Gene Expr. 19, 109-124 (2009).

2. Fazeli, P. K. et al. Marrow fat and bone-new perspectives. J. Clin. Endocrinol. Metab. 98, 935-945 (2013).

3. Abdallah, B. M. \& Kassem, M. New factors controlling the balance between osteoblastogenesis and adipogenesis. Bone 50, 540-545 (2012).

4. Chan, C. K. et al. Identification and specification of the mouse skeletal stem cell. Cell 160, 285-298 (2015).

5. Worthley, D. L. et al. Gremlin 1 identifies a skeletal stem cell with bone, cartilage, and reticular stromal potential. Cell 160, 269-284 (2015).

6. Jafari, A. et al. Legumain regulates differentiation fate of human bone marrow stromal cells and is altered in postmenopausal osteoporosis. Stem Cell Rep. 8, 373-386 (2017).

7. Tencerova, M. \& Kassem, M. The Bone Marrow-Derived Stromal Cells: Commitment and Regulation of Adipogenesis. Front. Endocrinol. 7, 127 (2016).

8. Moussaieff, A. et al. Glycolysis-mediated changes in acetyl-CoA and histone acetylation control the early differentiation of embryonic stem cells. Cell Metab. 21, 392-402 (2015)

9. Ryall, J. G., Cliff, T., Dalton, S. \& Sartorelli, V. Metabolic reprogramming of stem cell epigenetics. Cell Stem Cell 17, 651-662 (2015).

10. $\mathrm{Gu}, \mathrm{W}$. et al. Glycolytic metabolism plays a functional role in regulating human pluripotent stem cell state. Cell Stem Cell 19, 476-490 (2016).

11. Sinclair, $C$. et al. mTOR regulates metabolic adaptation of APCs in the lung and controls the outcome of allergic inflammation. Science 357, 1014-1021 (2017).

12. Wellen, K. E. \& Thompson, C. B. A two-way street: reciprocal regulation of metabolism and signalling. Nat. Rev. Mol. Cell Biol. 13, 270-276 (2012).

13. Hansson, J. et al. Highly coordinated proteome dynamics during reprogramming of somatic cells to pluripotency. Cell Rep. 2, 1579-1592 (2012).
14. Zhang, J. et al. Mitochondrial phosphatase PTPMT1 is essential for cardiolipin biosynthesis. Cell Metab. 13, 690-700 (2011).

15. Klimmeck, D. et al. Proteomic cornerstones of hematopoietic stem cell differentiation: distinct signatures of multipotent progenitors and myeloid committed cells. Mol. Cell Proteom. 11, 286-302 (2012).

16. Wellen, K. E. et al. ATP-citrate lyase links cellular metabolism to histone acetylation. Science 324, 1076-1080 (2009).

17. Lee, W. C., Guntur, A. R., Long, F. \& Rosen, C. J. Energy metabolism of the osteoblast: implications for osteoporosis. Endocr. Rev. 38, 255-266 (2017).

18. Folmes, C. D., Dzeja, P. P., Nelson, T. J. \& Terzic, A. Metabolic plasticity in stem cell homeostasis and differentiation. Cell Stem Cell 11, 596-606 (2012).

19. Post, S., Abdallah, B. M., Bentzon, J. F. \& Kassem, M. Demonstration of the presence of independent pre-osteoblastic and pre-adipocytic cell populations in bone marrow-derived mesenchymal stem cells. Bone 43, 32-39 (2008).

20. Taipaleenmaki, H., Abdallah, B. M., AlDahmash, A., Saamanen, A. M. \& Kassem, M. Wnt signalling mediates the cross-talk between bone marrow derived preadipocytic and pre-osteoblastic cell populations. Exp. Cell Res 317, 745-756 (2011).

21. Abdallah, B. M. et al. CD34 defines an osteoprogenitor cell population in mouse bone marrow stromal cells. Stem Cell Res. 15, 449-458 (2015).

22. Kassem, M. \& Bianco, P. Skeletal stem cells in space and time. Cell 160, 17-19 (2015).

23. Kohanski, R. A., Frost, S. C. \& Lane, M. D. Insulin-dependent phosphorylation of the insulin receptor-protein kinase and activation of glucose transport in 3T3-L1 adipocytes. J. Biol. Chem. 261, 12272-12281 (1986).

24. Guerin, P., El Mouatassim, S. \& Menezo, Y. Oxidative stress and protection against reactive oxygen species in the pre-implantation embryo and its surroundings. Hum. Reprod. Update 7, 175-189 (2001).

25. Fan, J. et al. Glutamine-driven oxidative phosphorylation is a major ATP source in transformed mammalian cells in both normoxia and hypoxia. Mol. Syst. Biol. 9, 712 (2013).

26. Fan, Y. et al. Parathyroid hormone directs bone marrow mesenchymal cell fate. Cell Metab. 25, 661-672 (2017).

27. Chang, E., Donkin, S. S. \& Teegarden, D. Parathyroid hormone suppresses insulin signaling in adipocytes. Mol. Cell Endocrinol. 307, 77-82 (2009).

28. Tencerova, M. et al. High-fat diet-induced obesity promotes expansion of bone marrow adipose tissue and impairs skeletal stem cell functions in mice. J. Bone Min. Res 33, 1154-1165 (2018).

29. Dahl, J. A. et al. Genetic and epigenetic instability of human bone marrow mesenchymal stem cells expanded in autologous serum or fetal bovine serum. Int. J. Dev. Biol. 52, 1033-1042 (2008).

30. Tencerova, M. et al. Obesity-associated hypermetabolism and accelerated senescence of bone marrow stromal stem cells suggest a potential mechanism for bone fragility. Cell Rep. 27, 2050-2062 e2056 (2019).

31. Zhang, J. et al. UCP2 regulates energy metabolism and differentiation potential of human pluripotent stem cells. EMBO J. 30, 4860-4873 (2011).

32. Kristensen, H. B., Andersen, T. L., Marcussen, N., Rolighed, L. \& Delaisse, J. M. Osteoblast recruitment routes in human cancellous bone remodeling. Am. J. Pathol. 184, 778-789 (2014).

33. Simsek, T. et al. The distinct metabolic profile of hematopoietic stem cells reflects their location in a hypoxic niche. Cell Stem Cell 7, 380-390 (2010).

34. Guntur, A. R. Osteoblast-like MC3T3-E1 cells prefer glycolysis for ATP production but adipocyte-like 3T3-L1 cells prefer oxidative phosphorylation. J. Bone Miner. Res. 33, 1052-1065 (2018).

35. Vander Heiden, M. G. et al. Metabolic pathway alterations that support cell proliferation. Cold Spring Harb. Symp. Quant. Biol. 76, 325-334 (2011).

36. Lunt, S. Y. \& Vander Heiden, M. G. Aerobic glycolysis: meeting the metabolic requirements of cell proliferation. Annu. Rev. Cell Dev. Biol. 27, 441-464 (2011).

37. Wei, J. et al. Glucose uptake and Runx2 synergize to orchestrate osteoblast differentiation and bone formation. Cell 161, 1576-1591 (2015).

38. Li, Z. et al. Glucose transporter-4 facilitates insulin-stimulated glucose uptake in osteoblasts. Endocrinology 157, 4094-4103 (2016).

39. Esen, E., Lee, S. Y., Wice, B. M. \& Long, F. PTH promotes bone anabolism by stimulating aerobic glycolysis via IGF signaling. J. Bone Min. Res. 30, 1959-1968 (2015).

40. Maridas, D. E. et al. Progenitor recruitment and adipogenic lipolysis contribute to the anabolic actions of parathyroid hormone on the skeleton. FASEB J. 33, 2885-2898 (2019).

41. Kim, S. P. et al. Fatty acid oxidation by the osteoblast is required for normal bone acquisition in a sex- and diet-dependent manner. JCI Insight 2, https://doi.org/ 10.1172/jci.insight.92704 (2017).

42. Ambrosi, T. H. et al. Adipocyte accumulation in the bone marrow during obesity and aging impairs stem cell-based hematopoietic and bone regeneration. Cell Stem Cell 20, 771-784 e776 (2017). 
14

43. Abdallah, B. M., Haack-Sorensen, M., Fink, T. \& Kassem, M. Inhibition of osteoblast differentiation but not adipocyte differentiation of mesenchymal stem cells by sera obtained from aged females. Bone 39, 181-188 (2006).

44. Qiu, W. et al. Patients with high bone mass phenotype exhibit enhanced osteoblast differentiation and inhibition of adipogenesis of human mesenchymal stem cells. J. Bone Min. Res. 22, 1720-1731, https://doi.org/10.1359/jbmr.070721 (2007).

45. Okada, T., Kawano, Y., Sakakibara, T., Hazeki, O. \& Ui, M. Essential role of phosphatidylinositol 3-kinase in insulin-induced glucose transport and antilipolysis in rat adipocytes. Studies with a selective inhibitor wortmannin. J. Biol. Chem. 269, 3568-3573 (1994).

46. Wu, M. et al. Multiparameter metabolic analysis reveals a close link between attenuated mitochondrial bioenergetic function and enhanced glycolysis dependency in human tumor cells. Am. J. Physiol. Cell Physiol. 292, C125-136 (2007).

47. Paglia, G. et al. Monitoring metabolites consumption and secretion in cultured cells using ultra-performance liquid chromatography quadrupole-time of flight mass spectrometry (UPLC-Q-ToF-MS). Anal. Bioanal. Chem. 402, 1183-1198 (2012).

48. Pluskal, T., Castillo, S., Villar-Briones, A. \& Oresic, M. MZmine 2: modular framework for processing, visualizing, and analyzing mass spectrometry-based molecular profile data. BMC Bioinforma. 11, 395 (2010).
49. Zhu, H. et al. A protocol for isolation and culture of mesenchymal stem cells from mouse compact bone. Nat. Protoc. 5, 550-560 (2010).

50. Houlihan, D. D. et al. Isolation of mouse mesenchymal stem cells on the basis of expression of Sca-1 and PDGFR-alpha. Nat. Protoc. 7, 2103-2111 (2012).

(i) Open Access This article is licensed under a Creative Commons Ay Attribution 4.0 International License, which permits use, sharing, adaptation, distribution and reproduction in any medium or format, as long as you give appropriate credit to the original author(s) and the source, provide a link to the Creative Commons license, and indicate if changes were made. The images or other third party material in this article are included in the article's Creative Commons license, unless indicated otherwise in a credit line to the material. If material is not included in the article's Creative Commons license and your intended use is not permitted by statutory regulation or exceeds the permitted use, you will need to obtain permission directly from the copyright holder. To view a copy of this license, visit http://creativecommons. org/licenses/by/4.0/.

(c) The Author(s) 2019 